Article

\title{
Synthesis, Spectroscopic Investigations (X-ray, NMR and TD-DFT), Antimicrobial Activity and Molecular Docking of 2,6-Bis(hydroxy(phenyl)methyl)cyclohexanone
}

\author{
Assem Barakat ${ }^{1,4, *, \dagger}$, Hazem A. Ghabbour ${ }^{2, \dagger}$, Abdullah Mohammed Al-Majid 1,†, \\ Saied M. Soliman ${ }^{3,4, \dagger}$, M. Ali ${ }^{1, \dagger}$, Yahia Nasser Mabkhot ${ }^{1, \dagger}$, Mohammed Rafi Shaik ${ }^{1, \dagger}$ \\ and Hoong-Kun Fun ${ }^{2,5, \dagger}$
}

1 Department of Chemistry, College of Science, King Saud University, P. O. Box 2455, Riyadh-11451, Saudi Arabia; E-Mails: amajid@ksu.edu.sa (A.M.A.-M.); mohamedali.eg25@gmail.com (M.A.); yahia@ksu.edu.sa (Y.N.M.); mshaik@ksu.edu.sa (M.R.S.) Department of Pharmaceutical Chemistry, College of Pharmacy, King Saud University, P. O. Box 2457, Riyadh 11451, Saudi Arabia; E-Mails: ghabbourh@yahoo.com (H.A.G.); hfun.c@ksu.edu.sa (H.-K.F.)

3 Department of Chemistry, Rabigh College of Science and Art, King Abdulaziz University, P. O. Box 344, Rabigh 21911, Saudi Arabia; E-Mail: saied1soliman@yahoo.com

4 Department of Chemistry, Faculty of Science, Alexandria University, P. O. Box 426, Ibrahimia, Alexandria 21321, Egypt

5 X-ray Crystallography Unit, School of Physics, Universiti Sains Malaysia, Penang 11800, Malaysia

$\dagger$ These authors contributed equally to this work.

* Author to whom correspondence should be addressed; E-Mail: ambarakat@ksu.edu.sa; Tel.: +966-11467-5884; Fax: +966-11467-5992.

Academic Editor: Jean Jacques Vanden Eynde

Received: 11 May 2015 / Accepted: 13 July 2015 / Published: 21 July 2015

\begin{abstract}
The synthesis of 2,6-bis(hydroxy(phenyl)methyl)cyclohexanone $\mathbf{1}$ is described. The molecular structure of the title compound 1 was confirmed by NMR, FT-IR, MS, CHN microanalysis, and X-ray crystallography. The molecular structure was also investigated by a set of computational studies and found to be in good agreement with the experimental data obtained from the various spectrophotometric techniques. The antimicrobial activity and molecular docking of the synthesized compound was investigated.
\end{abstract}


Keywords: Aldol product; cyclohexanone; X-ray; TGA; DFT; antimicrobial activity; molecular docking

\section{Introduction}

The Claisen-Schmidt reaction (cross-Aldol reaction) is a condensation reaction of aldehydes and carbonyl compounds leading to $\beta$-hydroxycarbonyl compounds and has been playing an important role in synthetic organic chemistry [1]. The bis(arylmethylidene)cycloalkanone moiety is a novel and versatile pharmacophore, as compounds bearing this structural unit possess a broad spectrum of biological activities such as cytotoxicity [2,3], cancer chemo-preventive [4], HIV-1 integrase inhibitory [5,6], cholesterol-lowering [7], antiangiogenic [8], quinine reductase inducing [9], and anti-oxidant [10] properties. The bis(arylmethylidene)cycloalkanones are used as a precursor for synthesis of a new class of tricyclic thiazolo[3,2-a] thiapyrano[4,3- $d$ ]pyrimidines, spiropyrrolidines which are antimicrobial and antifungal agents [11], and related analogues as potential anti-inflammatory agents [12], and other bioactive and novel heterocycles $[13,14]$. Thus, the synthesis of bis(arylmethylidene)cycloalkanones has attracted the attention of synthetic organic/medicinal chemists. The general approach involves cross-Aldol condensation of a cycloalkanone with an aromatic aldehyde [15], commonly catalyzed by a base [16] or an acid [17] and other compounds [18,19]. The condensation can be carried out using versatile reagents, such as $\mathrm{Cp}_{2} \mathrm{TiPh}_{2}$ [20], $\mathrm{Cp}_{2} \mathrm{ZrH}_{2}$ [21], $\mathrm{RuCl}_{3}$ [22], bis(p-methoxyphenyl)telluroxide (BMPTO) [23], $\mathrm{TiCl}_{3}\left(\mathrm{CF}_{3} \mathrm{SO}_{3}\right)$ [24], $\mathrm{SmI}_{3}$ [25,26], La3+-immobilized organic solid [27], $\mathrm{Mg}\left(\mathrm{HSO}_{4}\right)_{2}$ [28], $\mathrm{KF}-\mathrm{Al}_{2} \mathrm{O}_{3}$ [29], $\mathrm{BF}_{3} \cdot \mathrm{OEt}_{2}$ [30], $\mathrm{FeCl}_{3}$ [31], TMSCl/NaI [32], $\mathrm{InCl}_{3}$ [33], $\mathrm{SOCl}_{2}$ [34], TMSCl/Pd-C [35], $\mathrm{K}_{2} \mathrm{CO}_{3} / \mathrm{PEG}-400$ [36], $\mathrm{Yb}(\mathrm{OTf})_{3}$ [37], $\mathrm{Cu}(\mathrm{OTf})_{2}$ [38], molecular $\mathrm{I}_{2}$ [39], Et $3 \mathrm{~N}$ in the presence of $\mathrm{LiClO}_{4}$ [40], silica chloride [41], 1-methyl-3(2-(sulfooxy)ethyl)-1H-imidazol-3-ium chloride [42] and silica-supported silicaphosphinoxide (silphox, $\left[\mathrm{POCl}_{3-\mathrm{n}}\left(\mathrm{SiO}_{2}\right)_{\mathrm{n}}\right]$ ) or phosphorus pentoxide $\left(\mathrm{P}_{2} \mathrm{O}_{5} / \mathrm{SiO}_{2}\right)$ as heterogeneous reagents [43]. Despite the improvements offered by these routes, most of the reactions suffer from reverse and/or side reactions resulting in low yields of the desired products. One can assume that one challenge with a conventional Aldol approach is the reversibility of the Aldol reaction due to the unstabilized Aldol product. One group solved this problem [44] by using $N$-bocamide where the boc moiety rearranges to stabilize the resulting hydroxyl anion forcing the reaction towards product formation. This approach though, is mostly limited to aromatic aldehydes and gives modest yields for aliphatic aldehydes.

In the view of the above mentioned facts and in continuation of our interest [45-48], the structure of 2,6-bis(hydroxy(phenyl)methyl)cyclohexanone 1 was unambiguously deduced by single-crystal X-ray diffraction technique and elemental analysis. Also, the DFT/B3LYP calculations have been performed to study the molecular structure characteristics of the studied compound. The electronic and spectroscopic properties of the studied compound have been predicted using the same level of theory. The TD-DFT calculations were used to predict the possible electronic transitions. Natural bond orbital (NBO) calculations were performed to predict the natural atomic charges and study the different intramolecular charge transfer (ICT) interactions occurring in the studied system. The NMR chemical shifts are calculated using the gauge including atomic orbital (GIAO) method and used to assign the experimental 
results. The bioactivity of the synthesized product was tested by anti-microbial activity assay and also the molecular docking was investigated.

\section{Results and Discussion}

\subsection{Synthesis of Compound 1}

The title compound 1 was synthesized from a mixture of cyclohexanone and benzaldehyde (1:2) using aqueous diethylamine in excellent yield (85\%) at room temperature for $1 \mathrm{~h}$ as depicted in Scheme 1.

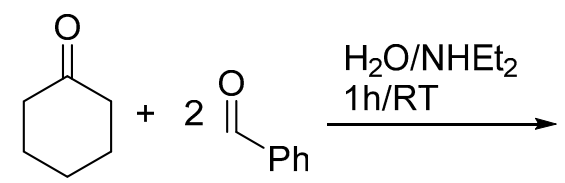<smiles>O=C1C(C(O)c2ccccc2)CCCC1C(O)c1ccccc1</smiles>

1

Scheme 1. Preparation of the title compound 1.

The structure of compound $\mathbf{1}$ was confirmed by analysis of its spectroscopic data including FT-IR, ${ }^{1} \mathrm{H}-,{ }^{13} \mathrm{C}-\mathrm{NMR}$ and X-ray structure of single crystal.

\subsection{Crystal Structure of Compound $\mathbf{1}$}

A clear colorless needle-like specimen of $\mathrm{C}_{20} \mathrm{H}_{22} \mathrm{O}_{3}$, approximate dimensions $0.68 \times 0.15 \times 0.14 \mathrm{~mm}$, was used for the X-ray crystallographic analysis (Figure 1). The integration of the data using a monoclinic, $C 2 / c$ unit cell yielded a total of 34,291 reflections to a maximum $\theta$ angle of 30.61, of which 4897 were independent (completeness $\left.=99.8 \%, R_{\text {int }}=3.1 \%, R_{\text {sig }}=2.24 \%\right)$ and $3976(81.19 \%)$ were greater than $2 \sigma\left(F^{2}\right)$. The final cell constants are $a=32.3262$ (14) $\AA, b=5.6987$ (2) $\AA, c=22.4859$ (7) $\AA, \beta=129.175$ $(2)^{\circ}$, volume $=3211.2(2) \AA^{3}$. Final refinement yields $\mathrm{R}\left[F^{2}>2 \sigma\left(F^{2}\right)\right]=0.048$ and $\mathrm{w} \mathrm{R}\left(F^{2}\right)=0.129$ where $\mathrm{w}=1 /\left[\sigma^{2}\left(F_{o}^{2}\right)+(0.0623 P)^{2}+3.520 P\right]$ and $P=\left(F_{o}^{2}+2 F_{c}^{2}\right) / 3$. Data were corrected for absorption effects using the multi-scan method (SADABS). On the basis of the final model, the calculated density was $1.284 \mathrm{Mg} / \mathrm{cm}^{3}$ and $F(000) 1328$ [49-51].

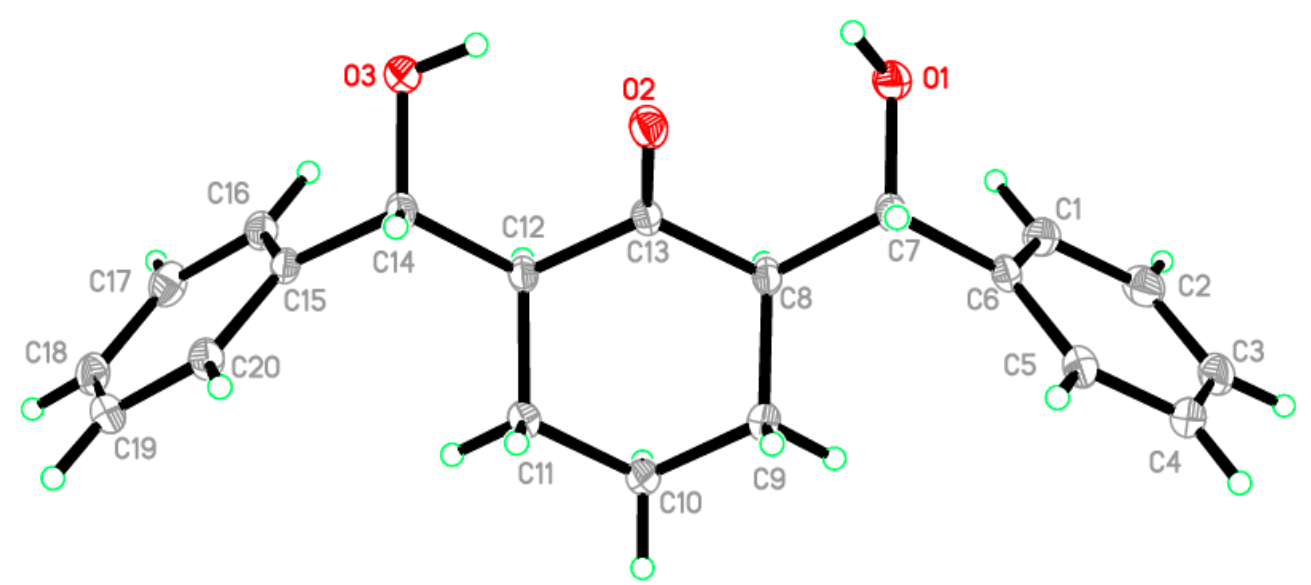

Figure 1. ORTEP diagram of the compound 1. Displacement ellipsoids are plotted at the $50 \%$ probability level. 
The asymmetric unit contains only one molecule of the compound. The molecular structure of compound 1 is composed of a cyclohexanone ring (C8-C13), which exhibits a chair conformation. The attached two hydroxyl methyl groups are disposed in equatorial configurations. (Figure 2). In the crystal structure, intermolecular $\mathrm{O} 1-\mathrm{H} 1 \mathrm{O} 1 \cdots \mathrm{O} 3$ hydrogen bonds are observed (Figure 3 and Tables 1 and 2). All geometric parameters $\left(\AA,{ }^{\circ}\right)$ and torsion angles of 1 are summarized in Tables S1 and 2 (Supplementary materials).

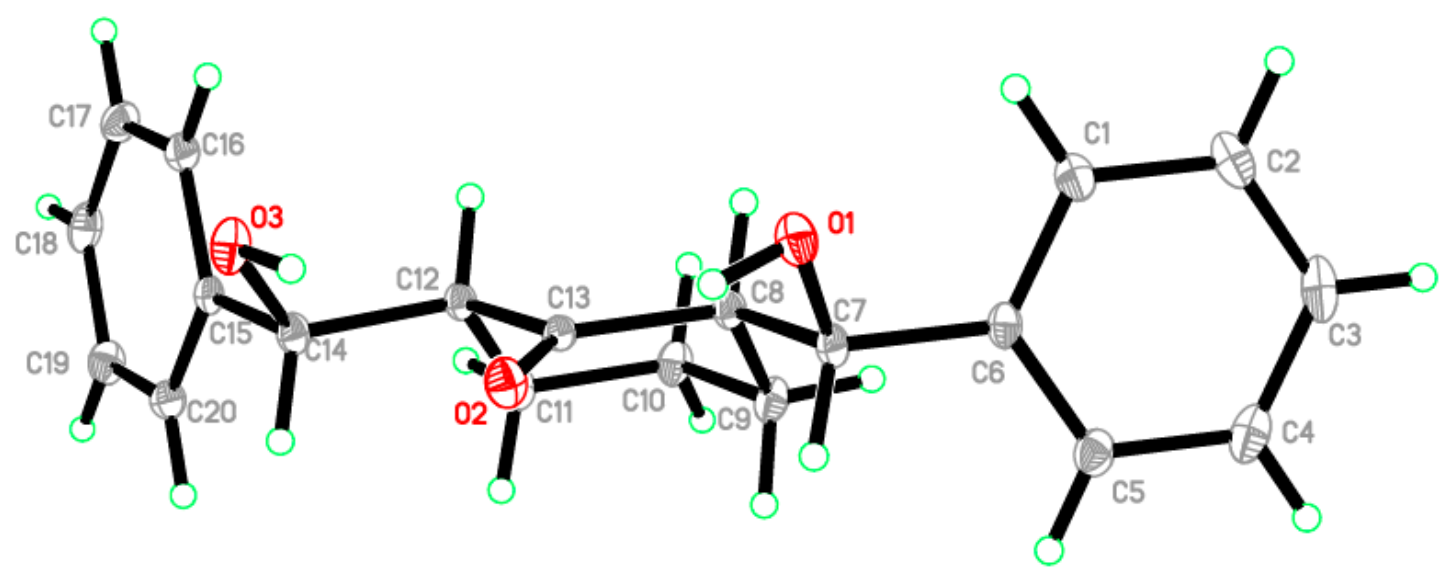

Figure 2. ORTEP diagram of the compound 1 drawn at 50\%; ellipsoids showing the chair conformation of cyclohexanone ring.

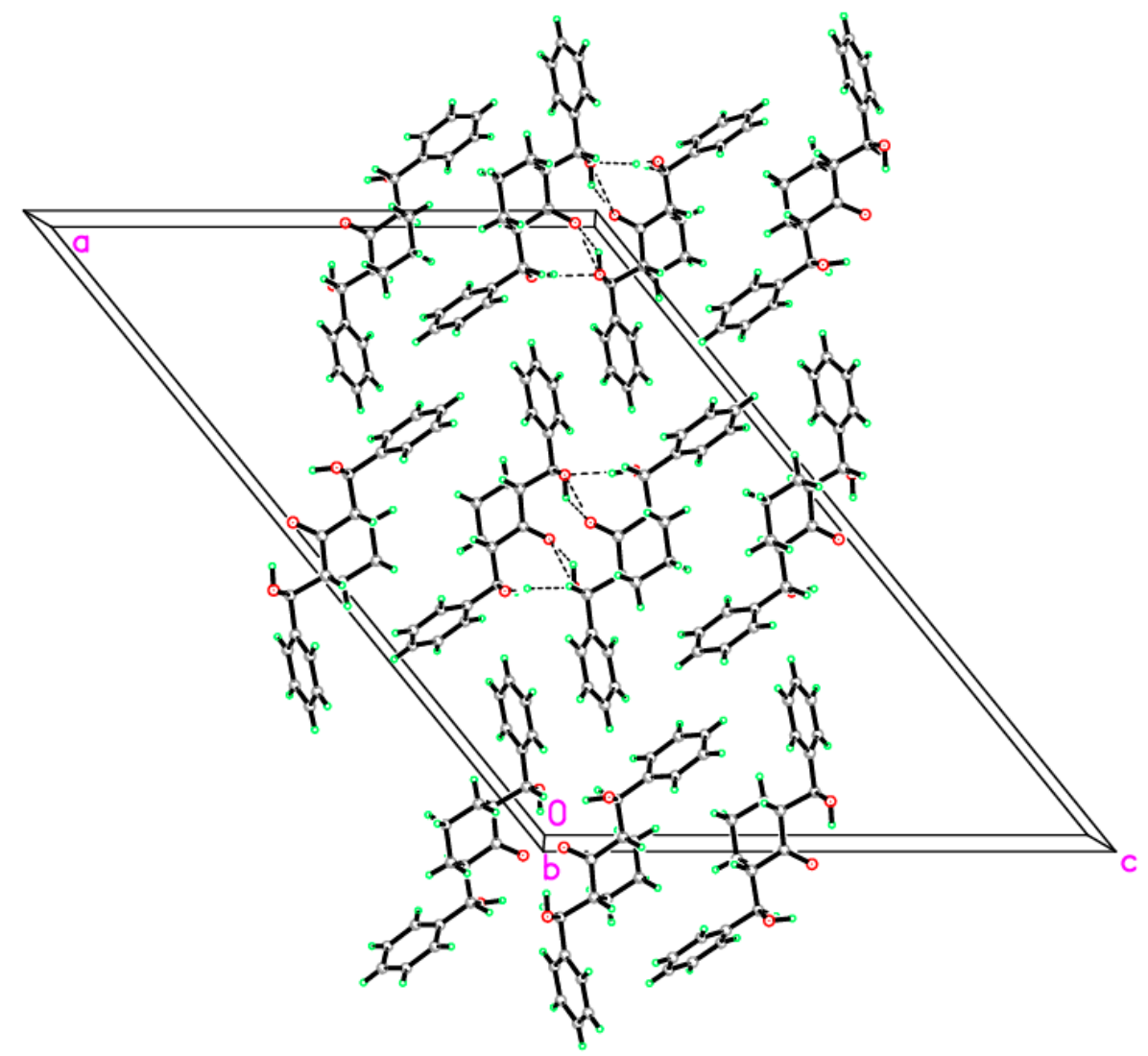

Figure 3. Crystal packing showing intermolecular $\mathrm{C}-\mathrm{H} \cdots \mathrm{O}$ and $\mathrm{N}-\mathrm{H} \cdots \mathrm{O}$ hydrogen bonds as dashed lines. 
Table 1. Crystal data of 1.

\begin{tabular}{cc}
\hline $\mathbf{C}_{\mathbf{2 0}} \mathbf{H}_{\mathbf{2 2}} \mathbf{O}_{\mathbf{3}}$ & $\boldsymbol{F} \mathbf{( 0 0 0 )}=\mathbf{1 3 2 8}$ \\
\hline Mr $=310.37$ & $D x=1.284 \mathrm{Mg} \mathrm{m}^{-3}$ \\
Monoclinic, $C 2 / c$ & $Z=8$ \\
$a=32.3262(14) \AA$ & Mo Ka radiation, $\lambda=0.71073 \AA$ \\
$b=5.6987(2) \AA$ & Cell parameters from 9876 reflections \\
$c=22.4859(7) \AA$ & $\theta=2.5-30.6^{\circ}$ \\
$\beta=129.175(2)^{\circ}$ & $\mu=0.09 \mathrm{~mm}^{-1}$ \\
$V=3211.2(2) \AA^{3}$ & $\mathrm{~T}=100 \mathrm{~K}$ \\
$0.68 \times 0.15 \times 0.14 \mathrm{~mm}$ & Needle, colourless \\
\hline
\end{tabular}

Data collection

\begin{tabular}{ll}
\hline Bruker APEX-II D8 Venture Diffractometer & 3976 Reflections With I > 2 $\mathbf{\sigma}(\mathbf{I})$ \\
\hline Radiation source: Mo K $\alpha$ radiation, $\lambda=0.71073 \AA$ & $R_{\mathrm{int}}=0.031$ \\
$\varphi$ and $\omega$ scans & $\theta_{\max }=30.6^{\circ}, \theta_{\min }=2.3^{\circ}$ \\
Absorption correction: multi-scan SADABS V2012/1 & $h=-45,46$ \\
(Bruker AXS Inc., Billerica, MA,USA) & $k=-7,8$ \\
$\mathrm{~T}_{\min }=0.91, \mathrm{~T}_{\max }=0.99$ & $l=-32,31$ \\
34291 measured reflections & \\
4897 independent reflections & \\
\hline
\end{tabular}

Refinement

\begin{tabular}{ll}
\hline Refinement on $\boldsymbol{F}^{\mathbf{2}}$ & Hydrogen Site Location: Mixed \\
\hline Least-squares matrix: full & $\mathrm{H}$ atoms treated by a mixture of independent and constrained refinement \\
$\mathrm{R}\left[F^{2}>2 \sigma\left(F^{2}\right)\right]=0.048$ & $\mathrm{w}=1 /\left[\sigma^{2}\left(F_{o}^{2}\right)+(0.0623 P) 2+3.520 P\right]$ where $P=\left(F_{o}^{2}+2 F_{c}^{2}\right) / 3$ \\
$\mathrm{wR}\left(F^{2}\right)=0.129$ & $(\Delta / \sigma) \max =0.001$ \\
$\mathrm{~S}=1.03$ & $\Delta \rho_{\max }=0.62 \mathrm{e} \cdot \AA^{-3}$ \\
4897 reflections & $\Delta \rho_{\min }=-0.19 \mathrm{e} \cdot \AA^{-3}$ \\
216 parameters & \\
\hline
\end{tabular}

Table 2. Hydrogen-bond geometry $\left(\AA,^{\circ}\right)$ of $\mathbf{1}$.

\begin{tabular}{ccccc}
\hline $\mathbf{D}-\mathbf{H} \cdots \mathbf{A}$ & $\mathbf{D}-\mathbf{H}$ & $\mathbf{H} \cdots \mathbf{A}$ & $\mathbf{D} \cdots \mathbf{A}$ & $\mathbf{D}-\mathbf{H} \cdots \mathbf{A}$ \\
\hline $\mathrm{O} 1-\mathrm{H} 1 \mathrm{O} 1 \cdots \mathrm{O} 3{ }^{\mathrm{i}}$ & $0.90(2)$ & $2.01(2)$ & $2.8799(15)$ & $162.1(16)$ \\
$\mathrm{O} 3-\mathrm{H} 1 \mathrm{O} 3 \cdots \mathrm{O} 2$ & $0.90(3)$ & $2.07(2)$ & $2.7835(15)$ & $136(2)$ \\
$\mathrm{O} 3-\mathrm{H} 1 \mathrm{O} 3 \cdots \mathrm{O} 2{ }^{\mathrm{i}}$ & $0.90(3)$ & $2.27(3)$ & $2.8491(17)$ & $121.9(18)$ \\
\hline
\end{tabular}

Symmetry code: (i) $-\mathrm{x}-1,-\mathrm{y},-\mathrm{z}$.

\subsection{Computational Details}

All the quantum chemical calculations of the studied compound were performed by applying DFT method with the B3LYP functional and 6-311G(d,p) basis set using Gaussian 03 software [52]. The input file was taken from the CIF obtained from our reported X-ray single crystal measurement. The geometry was optimized by minimizing the energies with respect to all the geometrical parameters without imposing any molecular symmetry constraints. GaussView4.1 [53] and Chemcraft [54] programs 
have been used to draw the structure of the optimized geometry. The frequency calculations showed no negative values confirming that the optimized geometry is an energy minimum. The electronic spectra of the studied compound were calculated by the TD-DFT method. The gauge including atomic orbital (GIAO) method was used for the NMR calculations. The ${ }^{1} \mathrm{H}$ and the ${ }^{13} \mathrm{C}$ isotropic shielding tensors referenced to the TMS calculations were carried out at the same level of theory. The Gaussian NBO 3.1 version were used to perform the natural bond orbital analyses [55].

\subsubsection{Optimized Molecular Geometry}

The optimized bond lengths and bond angles obtained for the studied compound using the B3LYP method with 6-311G(d,p) basis set are given in Table 3; while the atom numbering of the optimized structure is given in Figure 4. The studied compound possesses a $C_{1}$ point group. The optimized geometry of the studied compound was compared with the structural parameters obtained from the crystallographic information file (CIF) as shown in Figure 5. Some of these geometric parameters are overestimated while others are underestimated. The deviations of the calculated bond length and bond angle values from the experimental data did not exceed 0.012-0.014 $\AA$ (C15-Cl7 and C28-C31) and 2.27 (C25-C28-C31) respectively. Generally, the bond lengths and bond angles are predicted very well. The calculated $\mathrm{C}-\mathrm{C}-\mathrm{C}$ bond angle values of the benzene rings are in the range of $118.8-120.7^{\circ}$ (exp. $118.9-120.6^{\circ}$ ) [56]. The calculations predicted the O2...H45 intramolecular distance is $2.026 \AA$ (exp. $2.068 \AA$ ) while the $\mathrm{C} 30-\mathrm{O} 2 \ldots \mathrm{H} 45$ and $\mathrm{O} 3-\mathrm{H} 45 \ldots \mathrm{O} 2$ bond angles are $99.6^{\circ}\left(\exp .95 .6^{\circ}\right)$ and $131.2^{\circ}$ (exp. $136.0^{\circ}$ ) respectively. These results indicate the presence of intramolecular O...H H-bonding interactions. Moreover, the studied compound has three six membered rings, two are benzene and the third is cyclohexanone. The calculated $\mathrm{C}-\mathrm{C}-\mathrm{C}-\mathrm{C}$ dihedral angles of the two benzene rings do not exceed $1.0^{\circ}$ indicating, commonly, the perfectly planar structure of these rings. In contrast, the cyclohexanone ring is not planar, whereas the $\mathrm{C} 17, \mathrm{C} 19, \mathrm{C} 25$ and $\mathrm{C} 28$ atoms are in the same plane. The C22 lies below this plane while the $\mathrm{C} 30$ above it; as a result the cyclohexanone ring has a chair configuration (Figure 4).

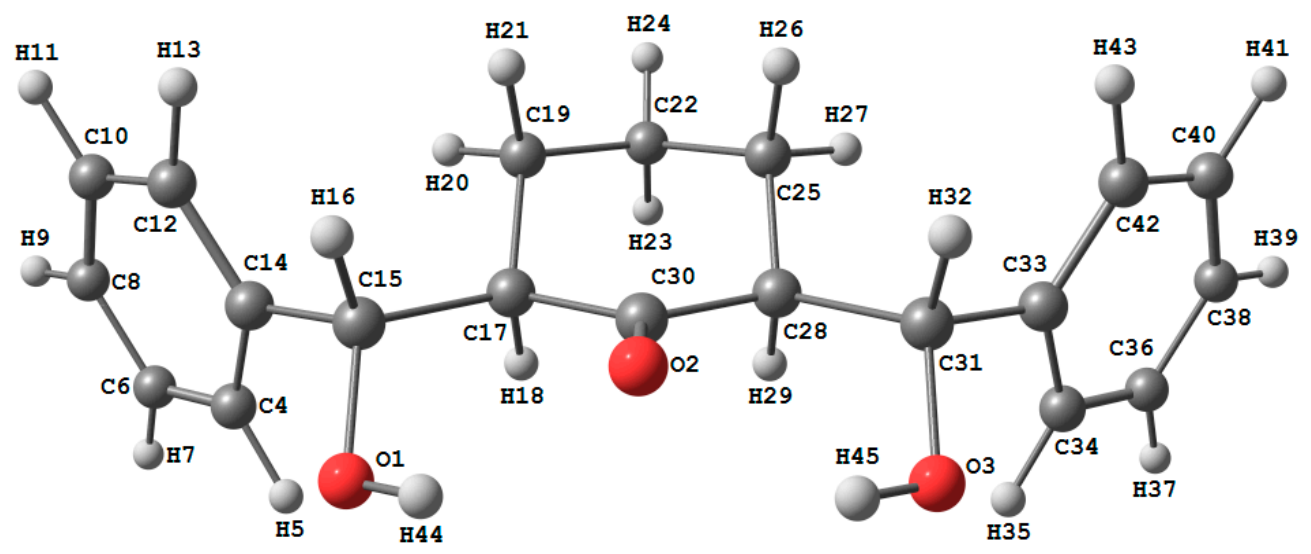

Figure 4. Cont. 


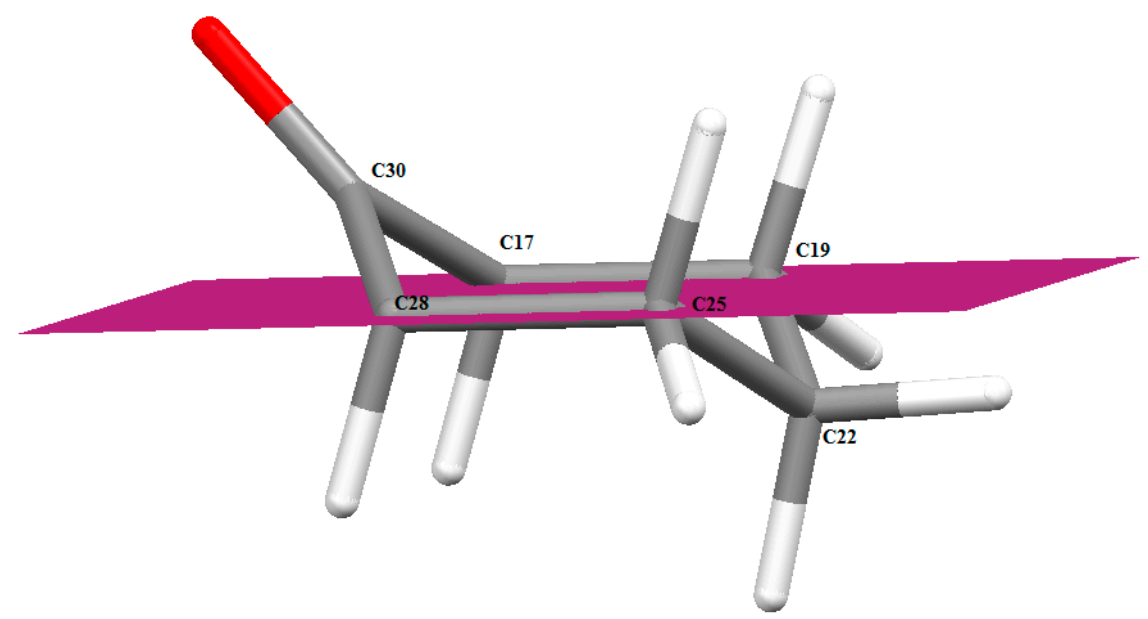

Figure 4. The optimized molecular structure of the studied compound (upper) and the chair form configuration of the cyclohexanone ring (lower).
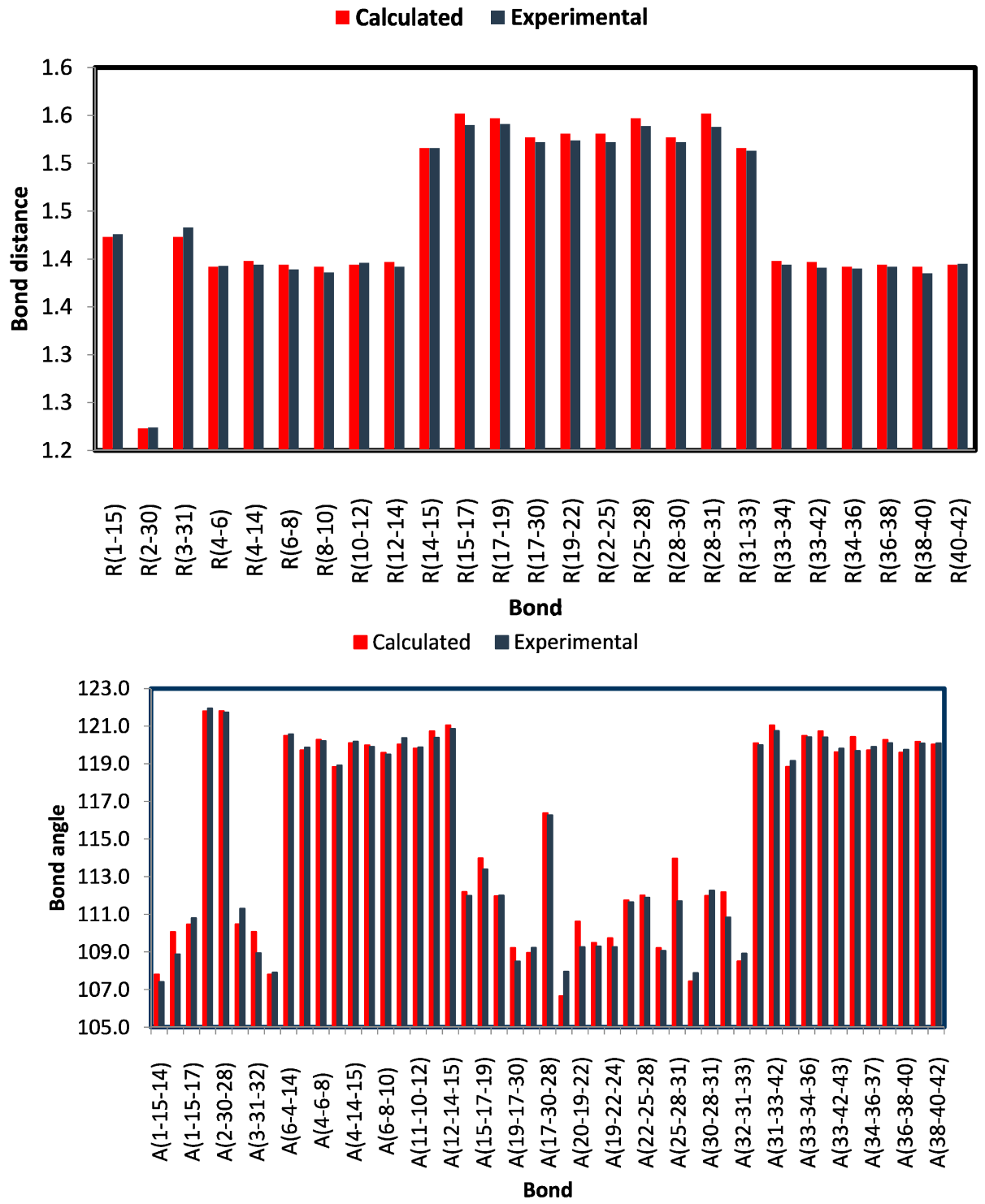

Figure 5. Comparison between the calculated and experimental geometric parameters (bond distances and angles) of the studied compounds. 
Table 3. The calculated and experimental geometric parameters of the studied compound using the DFT B3LYP/6-311G(d,p) method.

\begin{tabular}{|c|c|c|c|c|c|}
\hline Parameter & Calc. & Exp & Parameter & Calc. & Exp \\
\hline $\mathrm{R}(1-15)$ & 1.423 & 1.426 & $(7-6-8)$ & 120.0 & 119.9 \\
\hline $\mathrm{R}(2-30)$ & 223 & 224 & & 19.6 & 119.5 \\
\hline $\mathrm{R}(3-31)$ & 1.423 & 1.433 & $\mathrm{~A}(8-$ & 120.0 & 120.4 \\
\hline $\mathrm{R}(4-6)$ & 1.392 & 1.393 & $\mathrm{~A}(11-10-12)$ & 119.8 & 119.9 \\
\hline $\mathrm{R}(4-14)$ & 1.398 & 1.394 & $\mathrm{~A}(10$ & 120.7 & 120.4 \\
\hline $\mathrm{R}(6-8)$ & 1.394 & 1.389 & $\mathrm{~A}(12-14-15)$ & 121.1 & 120.9 \\
\hline $\mathrm{R}(8-10)$ & 1.392 & 1.386 & $\mathrm{~A}(14$ & 112.2 & 112.0 \\
\hline $\mathrm{R}(10-12)$ & 1.394 & 1.396 & $\mathrm{~A}(1$ & 114.0 & 113.4 \\
\hline $\mathrm{R}(12-14)$ & 1.397 & 1.392 & $\mathrm{~A}(15-1$ & 112.0 & 112.0 \\
\hline $\mathrm{R}(14$ & 1.516 & 1.516 & $\mathrm{~A}(1$ & 109.2 & 108.5 \\
\hline $\mathrm{R}(15-17)$ & 1.552 & 1.540 & $\mathrm{~A}(17$ & 109.0 & 109.2 \\
\hline $\mathrm{R}(17-$ & 1.547 & & $\mathrm{~A}(17$ & 116.4 & 116.3 \\
\hline $\mathrm{R}(17-30)$ & 1.527 & 1.522 & $\mathrm{~A}(20-$ & 106.7 & 108.0 \\
\hline $\mathrm{R}(19-22)$ & 1.531 & 1.524 & $\mathrm{~A}(20-$ & 110.6 & 109.3 \\
\hline$R(22-25)$ & 1.531 & 1.522 & $A(19-2$ & 109.5 & 109.3 \\
\hline $\mathrm{R}(25-28)$ & $1.54^{\prime}$ & 1.539 & $\mathrm{~A}(1 \mathrm{~S}$ & 109.7 & 109.3 \\
\hline $\mathrm{R}(28-30)$ & 1.527 & 1.522 & $\mathrm{~A}(19-2$ & 111.7 & 111.6 \\
\hline $\mathrm{R}(28-31)$ & 1.552 & 1.538 & $\mathrm{~A}(22-25-28)$ & 112.0 & 111.9 \\
\hline $\mathrm{R}(31-33)$ & 1.516 & 1.513 & $\mathrm{~A}(25$ & 109.2 & 109.1 \\
\hline $\mathrm{R}(33-3$ & 1.398 & 1.394 & $\mathrm{~A}(25$ & 114.0 & 111.7 \\
\hline $\mathrm{R}(33-42)$ & 1.397 & 1.391 & $\mathrm{~A}(2 \mathrm{~S}$ & 107.4 & 107.9 \\
\hline $\mathrm{R}(34-36)$ & 1.392 & 1.390 & $\mathrm{~A}(30$ & 112.0 & 112.3 \\
\hline $\mathrm{R}(36-38)$ & 1.394 & 1.392 & $\mathrm{~A}(28-$ & 112.2 & 110.8 \\
\hline $\mathrm{R}(38-40)$ & 1.392 & 1.385 & $\mathrm{~A}(32$ & 108.5 & 108.9 \\
\hline $\mathrm{R}(40-42)$ & 1.394 & 1.395 & $\mathrm{~A}(31-33-34)$ & 120.1 & 120.0 \\
\hline $\mathrm{R}(2-45)$ & 2.026 & 2.068 & $\mathrm{~A}(31-33-42)$ & 121.1 & 120.8 \\
\hline $\mathrm{A}(1-15-1$ & 107. & 107.4 & $\mathrm{~A}(34-3$ & 118.8 & 119.2 \\
\hline$A(1-15-16)$ & 110.1 & 108.9 & $\mathrm{~A}(33-$ & 120.5 & 120.4 \\
\hline$A(1-15-17)$ & 110.5 & 110.8 & $\mathrm{~A}(33-42-40)$ & 120.7 & 120.4 \\
\hline$A(2-30-17)$ & 121.8 & 122.0 & $\mathrm{~A}(33-42-43)$ & 119.6 & 119.8 \\
\hline$A(2-30-28)$ & 121.8 & 121.7 & $\mathrm{~A}(35-34-36)$ & 120.4 & 119.7 \\
\hline$A(3-31-28)$ & 110.5 & 111.3 & $\mathrm{~A}(34-36-37)$ & 119.7 & 119.9 \\
\hline$A(3-31-32)$ & 110.1 & 108.9 & $\mathrm{~A}(34-36-38)$ & 120.3 & 120.1 \\
\hline $\mathrm{A}(3-31-33)$ & 107.8 & 107.9 & $\mathrm{~A}(36-38-40)$ & 119.6 & 119.8 \\
\hline $\mathrm{A}(6-4-14)$ & 120.5 & 120.6 & $\mathrm{~A}(39-38-40)$ & 120.2 & 120.1 \\
\hline $\mathrm{A}(4-6-7)$ & 119.7 & 119.9 & $\mathrm{~A}(38-40-42)$ & 120.0 & 120.1 \\
\hline $\mathrm{A}(4-6-8)$ & 120.3 & 120.2 & $\mathrm{~A}(30-2-45)$ & 99.6 & 95.6 \\
\hline $\mathrm{A}(4-14-12)$ & 118.8 & 118.9 & $\mathrm{~A}(3-45-2)$ & 131.2 & 136.0 \\
\hline $\mathrm{A}(4-14-15)$ & 120.1 & 120.2 & & & \\
\hline
\end{tabular}

\subsubsection{Natural Atomic Charge}

The calculated natural charges (NAC) at different atomic sites are given in Table 4. The $\mathrm{O}^{-}$atoms are the most electronegative atomic sites in the molecule. The calculated natural charge densities at these atoms are in the range -0.6239 to -0.7486 . The two oxygen atoms of the $\mathrm{OH}$ groups are more 
electronegative than the carbonyl oxygen. All the H-toms are electropositive, where the most electropositive $\mathrm{H}$-sites are $\mathrm{H} 44$ and $\mathrm{H} 45(+0.4719)$ as these protons attached to the most electronegative $\mathrm{O}$-atoms in the molecule. The rest of $\mathrm{H}$-atoms have natural atomic charge values in the range of 0.1714-0.2258. Of these protons, the H18 and H29 are more electropositive than others. The H18 and $\mathrm{H} 29$ atoms are affected by the high electron withdrawing character of the $\mathrm{C}=\mathrm{O}$ group. In contrast, the $\mathrm{C}$-atoms have negative natural charges except $\mathrm{C} 15, \mathrm{C} 30$ and $\mathrm{C} 31$ which are bonded to $\mathrm{O} 1, \mathrm{O} 2$ and $\mathrm{O} 3$ atoms respectively. The carbonyl carbon (C30) has the highest positive NAC value.

Table 4. The natural atomic charges calculated at the B3LYP/6-311G(d,p).

\begin{tabular}{|c|c|c|c|}
\hline Atom & NAC & Atom & NAC \\
\hline $\mathrm{O} 1$ & -0.7486 & $\mathrm{H} 24$ & 0.2056 \\
\hline $\mathrm{O} 2$ & -0.6239 & $\mathrm{C} 25$ & -0.3775 \\
\hline $\mathrm{O} 3$ & -0.7486 & $\mathrm{H} 26$ & 0.1879 \\
\hline $\mathrm{C} 4$ & -0.1952 & $\mathrm{H} 27$ & 0.2196 \\
\hline H5 & 0.2157 & $\mathrm{C} 28$ & -0.3173 \\
\hline C6 & -0.1898 & $\mathrm{H} 29$ & 0.2258 \\
\hline H7 & 0.2006 & $\mathrm{C} 30$ & 0.6563 \\
\hline $\mathrm{C} 8$ & -0.2010 & $\mathrm{C} 31$ & 0.1467 \\
\hline H9 & 0.2003 & H32 & 0.1714 \\
\hline $\mathrm{C} 10$ & -0.1939 & $\mathrm{C} 33$ & -0.0406 \\
\hline H11 & 0.2005 & C34 & -0.1952 \\
\hline $\mathrm{C} 12$ & -0.2057 & H35 & 0.2157 \\
\hline H13 & 0.1993 & $\mathrm{C} 36$ & -0.1898 \\
\hline $\mathrm{C} 14$ & -0.0406 & H37 & 0.2006 \\
\hline $\mathrm{C} 15$ & 0.1467 & C38 & -0.2010 \\
\hline H16 & 0.1714 & H39 & 0.2003 \\
\hline $\mathrm{C} 17$ & -0.3172 & $\mathrm{C} 40$ & -0.1939 \\
\hline H18 & 0.2258 & H41 & 0.2005 \\
\hline $\mathrm{C} 19$ & -0.3776 & $\mathrm{C} 42$ & -0.2057 \\
\hline $\mathrm{H} 20$ & 0.2196 & H43 & 0.1993 \\
\hline $\mathrm{H} 21$ & 0.1879 & H44 & 0.4719 \\
\hline $\mathrm{C} 22$ & -0.3674 & $\mathrm{H} 45$ & 0.4719 \\
\hline $\mathrm{H} 23$ & 0.1897 & & \\
\hline
\end{tabular}

\subsubsection{Molecular Electrostatic Potential (MEP)}

Electrostatic potential maps are very useful three-dimensional diagrams used to visualize the charge distributions and charge related properties of molecules. The MEP is generated by overlapping the VdW radii of all atoms in the molecule so that its map reflects the molecule boundaries, and allows visualization of the size and shape of molecules. Also, the MEP picture has been used to predict the reactive sites for electrophilic and nucleophilic attack, and in studies of biological recognition and hydrogen bonding interactions [57,58].The MEP of the studied compound calculated using the B3LYP method with 6-311G(d,p) basis set is shown in Figure 6. The studied molecule has three O-atoms that might act as proton acceptor sites. It can be seen from this figure, that the negative regions (red) are mainly localized over the O-atoms of the hydroxyl groups. The $\mathrm{O} 1$ and $\mathrm{O} 3$ have more negative MEP values than the 
carbonyl oxygen $(\mathrm{O} 2)$; hence $\mathrm{O} 1$ and $\mathrm{O} 3$ atoms are the most reactive towards the intermolecular $\mathrm{H}$-bonding interactions as $\mathrm{H}$-acceptor. In contrast, the maximum positive regions (blue) are distributed over the H-atoms (H44 and H45) which are the most reactive sites to nucleophilic attack [59]. From this point of view, the $\mathrm{O} 1-\mathrm{H} 44$ and $\mathrm{O} 3-\mathrm{H} 45$ are the most reactive $\mathrm{H}$-donors for the intermolecular $\mathrm{H}$-bonding interactions. In agreement with the reported X-ray structure the intermolecular $\mathrm{O}-\mathrm{H}$...O-H intermolecular $\mathrm{H}$-bonding interactions are stronger than the $\mathrm{OH} \cdots \mathrm{O}=\mathrm{C}$ one.

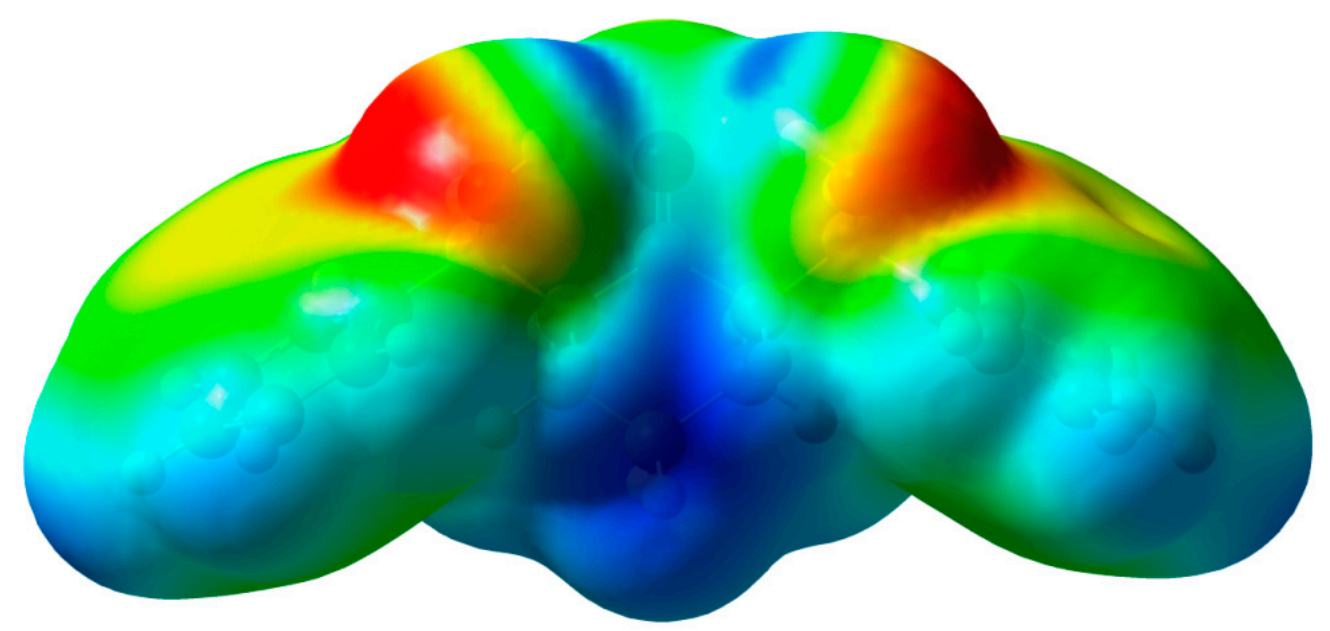

Figure 6. Molecular Electrostatic potentials (MEP) mapped on the electron density surface calculated by the DFT/B3LYP method.

\subsubsection{Nonlinear Optical Properties}

Nonlinear optical materials were used as key materials for photonic communications, which use light instead of electrons for data transmission. With the development of laser technology, nonlinear optical materials have been extensively applied to industry, national defense, medicine and research [60,61]. Several organic materials were used for such applications. These organic compounds were characterized by their high polarizability $\left(\alpha_{0}\right)$ and low HOMO-LUMO gap $(\Delta \mathrm{E})$. The $\alpha_{0}$ and $\Delta \mathrm{E}$ values of the studied compound are calculated to be $220.17 \mathrm{Bohr}^{3}$ and $5.3767 \mathrm{eV}$ respectively. The polarizability of the studied compound is eight times higher than urea. In addition, the studied compound has a lower energy gap $(\Delta \mathrm{E})$ compared to urea. Based on these calculations, the studied molecule is considered as a better NLO material than this reference molecule used in literature [62].

\subsubsection{Frontier Molecular Orbitals}

The properties of the frontier molecular orbitals (FMOs) are very useful for physicists and chemists. The electron densities of these FMOs were used for predicting the most reactive position in $\pi$-electron systems and also explained several types of reactions in conjugated systems [63]. Moreover, eigenvalues of the lowest unoccupied molecular orbital (LUMO) and the highest occupied molecular orbital (HOMO) and their energy gap reflect the chemical reactivity of the molecule. Recently the energy gap between HOMO and LUMO has been used to prove the bioactivity from intramolecular charge transfer (ICT) [64,65]. The HOMO-LUMO energy gap for the studied compound is calculated by B3LYP/6-311G(d,p). The HOMO and LUMO pictures are shown in Figure 7. It is found that the HOMO 
level is mainly localized on the benzene ring $\pi$-system and extended to the $\mathrm{C} 31-\mathrm{C} 28, \mathrm{C} 30=\mathrm{O} 2$ and C17-C15 bonds. The LUMO is located mainly on the $\mathrm{C}=\mathrm{O}$ group of the cyclohexanone ring. The Еномо and ELUmo are calculated to be $-6.7607 \mathrm{eV}$ and $-1.3840 \mathrm{eV}$ respectively. The HOMO-LUMO energy gap $(\Delta \mathrm{E})$ represents the lowest energy electronic transition. In the studied compound, the HOMO-LUMO energy gap of the studied compound is $5.3767 \mathrm{eV}$ (Figure 7). This electron transition belongs mainly to $\pi-\pi^{*}$ excitation.

The accurate electronic transitions were calculated using the time-dependent density functional theory (TD-DFT). The twenty spin allowed singlet-singlet electronic transitions calculated using the TD-DFT method and are shown in Table S3 (Supplementary Information). The calculated electronic spectrum is shown in Figure 8. The calculations predicted electronic transitions bands at $202.9 \mathrm{~nm}$, 213.2, $243.8 \mathrm{~nm}, 256 \mathrm{~nm}$ and $294.6 \mathrm{~nm}$. The first two bands were observed experimentally at 204 and $231 \mathrm{~nm}$, respectively. The latter is due to the electronic transitions from $\mathrm{H} \rightarrow \mathrm{L}+1(71 \%)$ and $\mathrm{H}-4 \rightarrow \mathrm{L}+1$ $(11 \%)$. The rest of the calculated electronic transition bands have low intensity and have no importance in the gas phase. In the experimental spectra, the longest wavelength transition band is observed at $328 \mathrm{~nm}$ while calculated at $294.6 \mathrm{~nm}$. The medium effects could be the main reason for the difference between the experimental and calculated values.
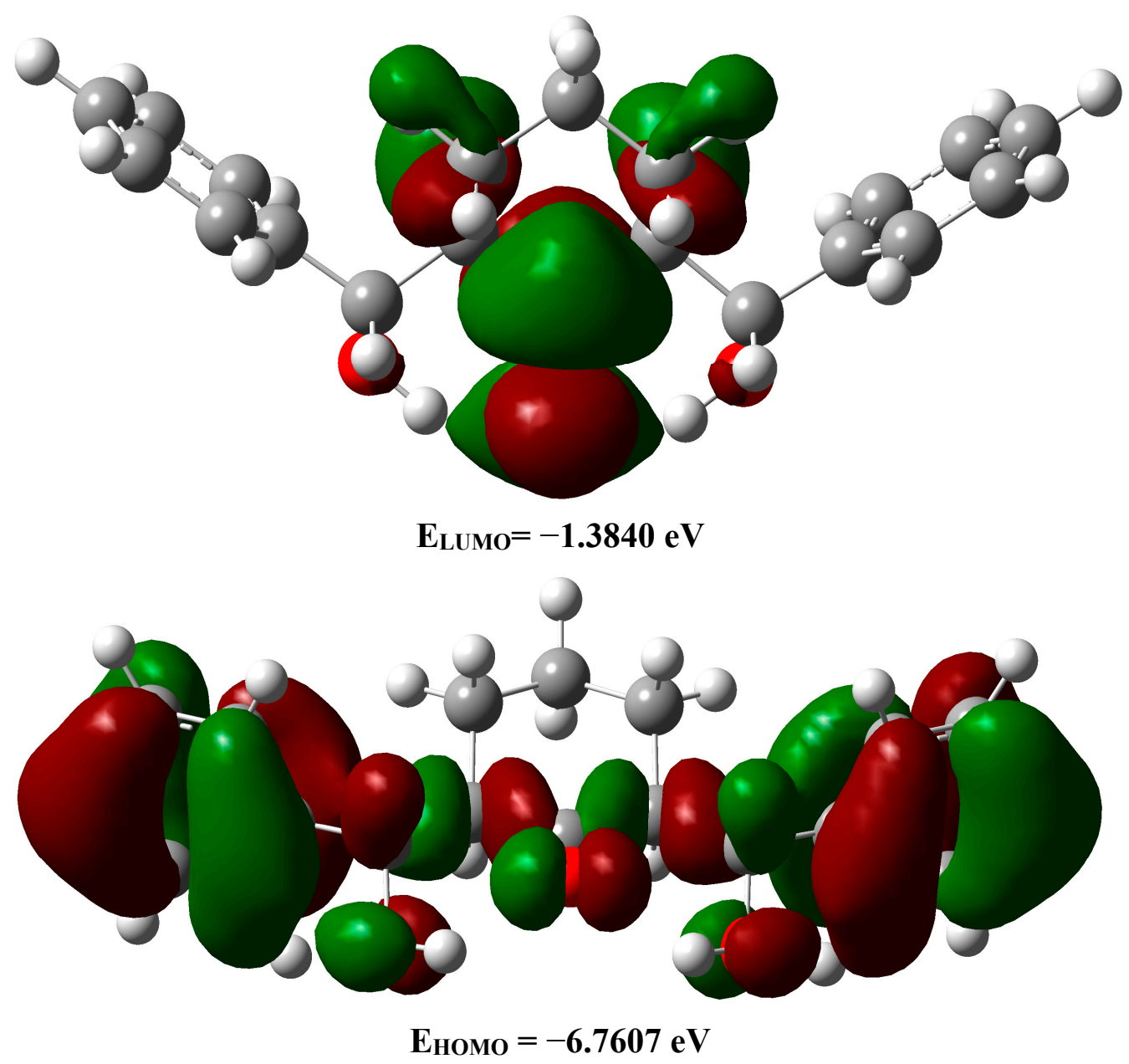

Figure 7. The ground state isodensity surface plots for the frontier molecular orbitals. 


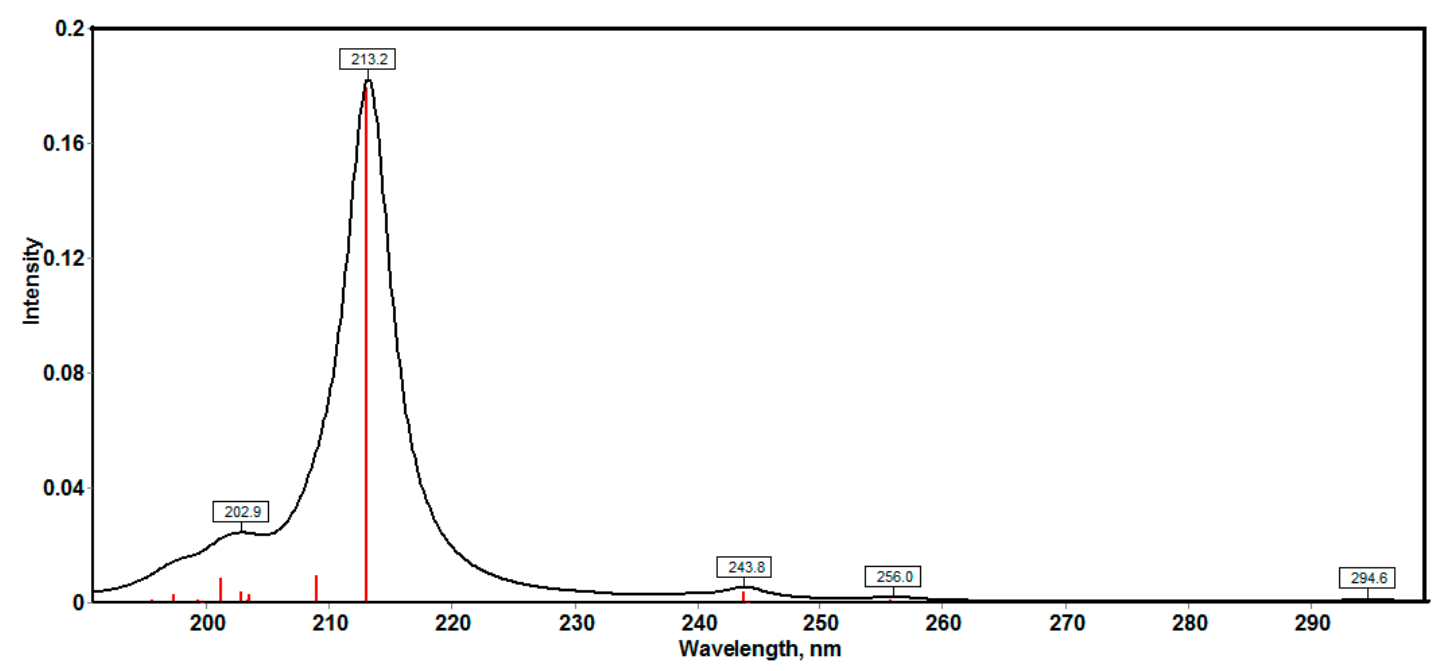

Figure 8. The calculated electronic spectra of the studied compound using the TD-DFT method.

\subsubsection{NMR Spectra}

The isotropic magnetic shielding (IMS) values calculated using the GIAO approach at the 6-311G(d,p) level are used to predict the ${ }^{13} \mathrm{C}$ and ${ }^{1} \mathrm{H}$ chemical shifts $\left(\delta_{\text {calc }}\right)$ for the studied compound and the results are correlated to the experimental NMR data $\left(\delta_{\exp }\right)$ in $\mathrm{CDCl}_{3}$ solvent. The experimental and theoretical values for ${ }^{1} \mathrm{H}$ - and ${ }^{13} \mathrm{C}$-NMR chemical shifts of the studied compound are given in Table S4 (Supplementary Information). According to these results, the calculated chemical shifts comply with the experimental findings. As shown in Figure 9, good correlations between the experimental and the calculated chemical shifts for carbon $\left(\mathrm{R}^{2}=0.9957\right)$ and proton $\left(\mathrm{R}^{2}=0.9860\right)$ were obtained.

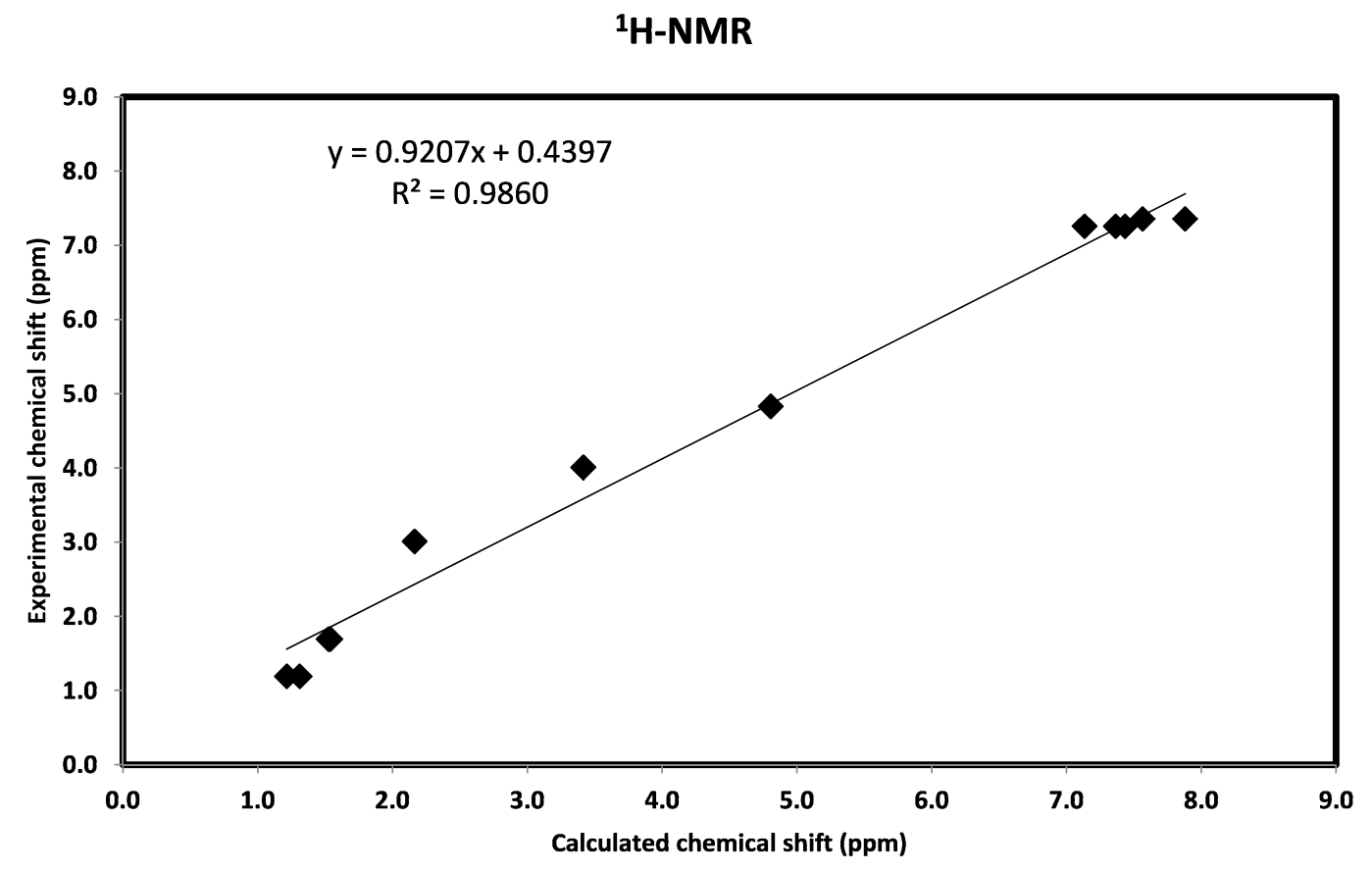

Figure 9. Cont. 


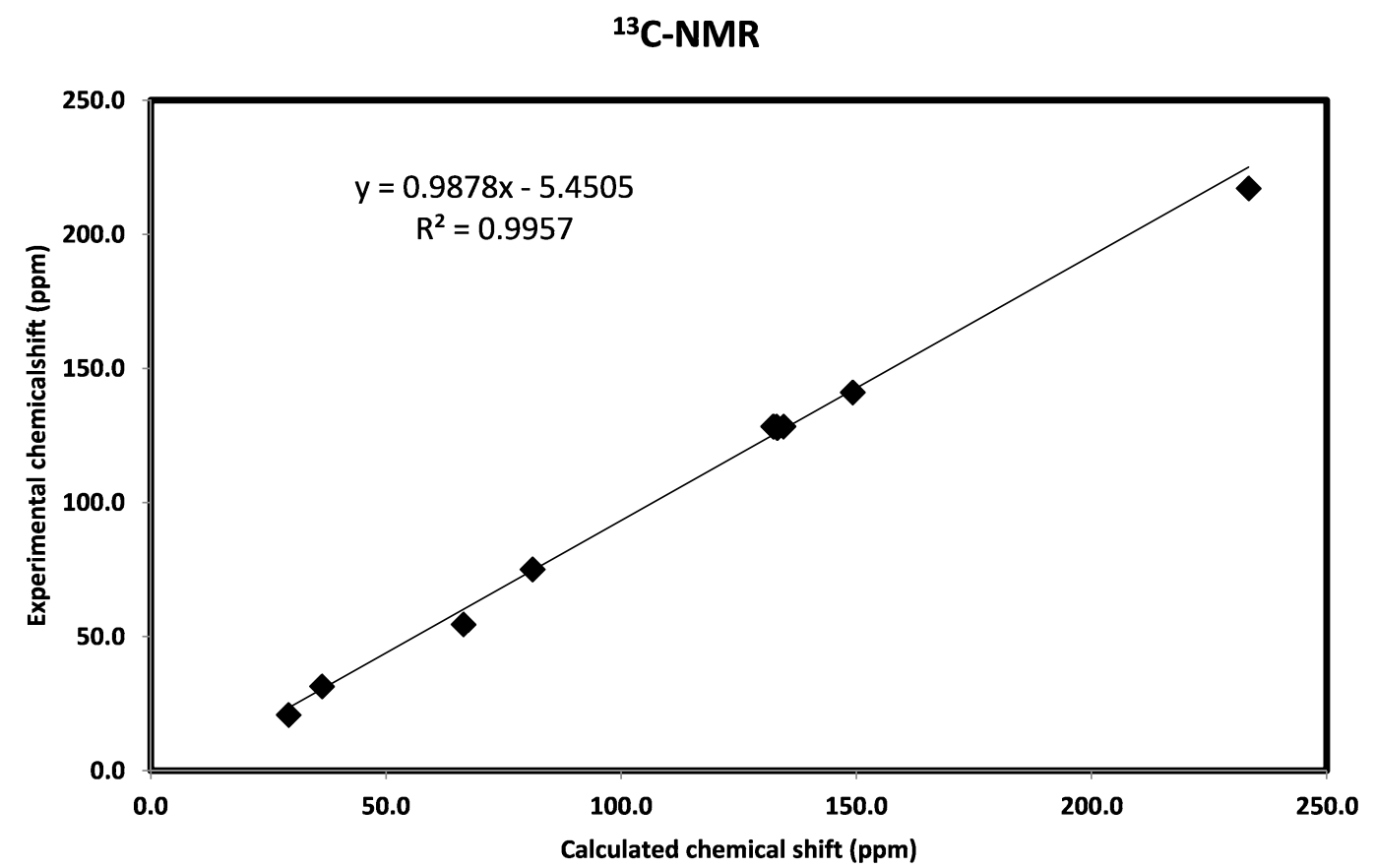

Figure 9. The correlation graph between calculated and experimental ${ }^{1} \mathrm{H}-\mathrm{NMR}$ and ${ }^{13} \mathrm{C}-\mathrm{NMR}$ chemical shifts of the studied compound.

\subsubsection{Natural Bond Orbital Analysis}

The occupancy of electrons and p-character in significant natural bond orbitals (NBO) for the studied compound are given in Table S5 (Supplementary Information). It is noted that, the hydrogen atoms have almost $0 \%$ of $\mathrm{p}$-character for all $\mathrm{C}-\mathrm{H}$ and $\mathrm{O}-\mathrm{H}$ bonds. In contrast, $100 \% p$-character was observed in both the atoms in $\pi$-bonding of the $\mathrm{C}-\mathrm{C}$ and $\mathrm{C}-\mathrm{O}$ bonds. Similarly, almost $100 \% p$-character was observed in the second lone pair of all O-atoms.

It is well known that the ideal $\mathrm{sp}^{2}$ hybrid orbital has $66.67 \%$ p-character while the ideal $\mathrm{sp}^{3}$ hybrid orbital has $75.00 \%$ p-character. The BD(1)C4-C6 orbital with 1.9770 electrons has $50.24 \%$ C4 character (64.06\%p) and 49.76\% C6 character (63.70\%p). On the other hand, the BD(1)C17-C19 orbital with 1.9593 electrons has $51.39 \% \mathrm{C} 17$ character $(73.03 \% \mathrm{p})$ and $48.61 \% \mathrm{C} 19$ character $(72.38 \% \mathrm{p})$. The BD(1)O1-C15 orbital with 1.9891 electrons has $66.59 \%$ O1 character $(69.79 \%$ p) and $33.41 \% \mathrm{C} 15$ character $(79.37 \% \mathrm{p})$. The $\mathrm{BD}(1) \mathrm{O} 2-\mathrm{C} 30$ orbital with 1.9943 electrons has $67.29 \% \mathrm{O} 2$ character (55.69\%p) and 32.71\% C30 character (71.04\%p). The two C-atoms forming the C-C hybrids have almost the same $\%$ electron density (\%ED). In contrast, the more electronegative O-atoms have higher electron density and lower \%p characters than the C-atom bonded to it. The higher \%ED on the $\mathrm{O}$-atom is due to its higher electronegativity than carbon. As a result, the NBO analyses showed that all the $\mathrm{C}-\mathrm{O}$ and $\mathrm{C}=\mathrm{O}$ bond orbitals are polarized towards the oxygen atoms. The percentage polarization of the $\mathrm{O}$-atoms for these bond hybrids are in the range of $81.60 \%-86.24 \%$. Therefore, they provide higher electron density on the oxygen atoms, which is responsible for the polarity of the studied compound (3.9588D). 


\section{Second-Order Perturbation Theory}

The natural bond orbital (NBO) calculations were performed in order to understand various interactions between the filled NBOs of one bond and vacant orbitals of another one, which is a measure of the intramolecular delocalization of electrons. The stabilization energies $\mathrm{E}^{(2)}$ deduced from the NBO calculations for the most significant intramolecular charge transfer interactions are reported in Table 5. The larger the $\mathrm{E}^{(2)}$ value, the more intensive is the interaction between electron donor and electron acceptor NBOs, i.e., the greater the extent of conjugation of the whole system [66]. The energy of these interactions can be estimated by the second-order perturbation theory [67]. The ICT interactions formed by the orbital overlap between $\pi \rightarrow \pi^{*}$ and $n \rightarrow \sigma^{*}$ causing stabilization of the system up to $21.51 \mathrm{kcal} / \mathrm{mol}$. The $\mathrm{LP}(2) \mathrm{O} 1 \rightarrow \mathrm{BD} *(1) \mathrm{C} 15-\mathrm{C} 17, \mathrm{LP}(2) \mathrm{O} 2 \rightarrow \mathrm{BD}^{*}(1) \mathrm{C} 17-\mathrm{C} 30, \mathrm{LP}(2) \mathrm{O} 2 \rightarrow \mathrm{BD} *(1) \mathrm{C} 28-\mathrm{C} 30$ and $\mathrm{LP}(2) \mathrm{O} 3 \rightarrow \mathrm{BD} *(1) \mathrm{C} 28-\mathrm{C} 31 \mathrm{ICT}$ have the $\mathrm{E}^{(2)}$ values of $6.81,18.04,18.04$ and $6.81 \mathrm{kcal} / \mathrm{mol}$. These results indicate the presence of some electron delocalization from the second lone pair of each oxygen atom to the neighbouring $\mathrm{C}-\mathrm{C}$ bonds. It seems that the ICT interactions from the $\mathrm{LP}(2) \mathrm{O} 2$ of the carbonyl group are more intensive than that for the $\mathrm{LP}(2) \mathrm{O} 1$ and $\mathrm{LP}(2) \mathrm{O} 3$ of the hydroxyl groups. Moreover, the LP(2)O2 $\rightarrow$ BD*(1)O1-H44/BD*(1)O3-H45 ICT interactions have stabilization energies of 2.69 and $2.70 \mathrm{kcal} / \mathrm{mol}$ respectively which indicate that the $\mathrm{O} \cdots \mathrm{H}$ intramolecular $\mathrm{H}$-bonding are weak interactions.

Table 5. The second order perturbation energies $\mathrm{E}^{(2)}(\mathrm{kcal} / \mathrm{mol})$ of the most important charge transfer interactions (donor-acceptor) of the studied compound using B3LYP method.

\begin{tabular}{|c|c|c|}
\hline Donor NBO (i) & Acceptor NBO (j) & $\mathrm{E}^{(2)} \mathrm{kcal} / \mathrm{mol}$ \\
\hline $\mathrm{BD}(2) \mathrm{C} 4-\mathrm{C} 6$ & $\mathrm{BD}^{*}(2) \mathrm{C} 8-\mathrm{C} 10$ & 20.76 \\
\hline $\mathrm{BD}(2) \mathrm{C} 4-\mathrm{C} 6$ & BD*(2)C12-C14 & 21.51 \\
\hline $\mathrm{BD}(2) \mathrm{C} 8-\mathrm{C} 10$ & $\mathrm{BD} *(2) \mathrm{C} 4-\mathrm{C} 6$ & 20.08 \\
\hline $\mathrm{BD}(2) \mathrm{C} 8-\mathrm{C} 10$ & BD*(2)C12-C14 & 19.86 \\
\hline $\mathrm{BD}(2) \mathrm{C} 12-\mathrm{C} 14$ & $\mathrm{BD} *(2) \mathrm{C} 4-\mathrm{C} 6$ & 19.53 \\
\hline $\mathrm{BD}(2) \mathrm{C} 12-\mathrm{C} 14$ & $\mathrm{BD}^{*}(2) \mathrm{C} 8-\mathrm{C} 10$ & 21.03 \\
\hline $\mathrm{BD}(2) \mathrm{C} 33-\mathrm{C} 42$ & $\mathrm{BD}^{*}(2) \mathrm{C} 34-\mathrm{C} 36$ & 19.53 \\
\hline $\mathrm{BD}(2) \mathrm{C} 33-\mathrm{C} 42$ & $\mathrm{BD}^{*}(2) \mathrm{C} 38-\mathrm{C} 40$ & 21.02 \\
\hline $\mathrm{BD}(2) \mathrm{C} 34-\mathrm{C} 36$ & $\mathrm{BD}^{*}(2) \mathrm{C} 33-\mathrm{C} 42$ & 21.51 \\
\hline $\mathrm{BD}(2) \mathrm{C} 34-\mathrm{C} 36$ & $\mathrm{BD}^{*}(2) \mathrm{C} 38-\mathrm{C} 40$ & 20.76 \\
\hline $\mathrm{BD}(2) \mathrm{C} 38-\mathrm{C} 40$ & $\mathrm{BD} *(2) \mathrm{C} 33-\mathrm{C} 42$ & 19.86 \\
\hline $\mathrm{BD}(2) \mathrm{C} 38-\mathrm{C} 40$ & $\mathrm{BD}^{*}(2) \mathrm{C} 34-\mathrm{C} 36$ & 20.08 \\
\hline $\mathrm{LP}(2) \mathrm{O} 1$ & BD*(1)C15-C17 & 6.81 \\
\hline $\mathrm{LP}(2) \mathrm{O} 2$ & $\mathrm{BD}^{*}(1) \mathrm{C} 17-\mathrm{C} 30$ & 18.04 \\
\hline $\mathrm{LP}(2) \mathrm{O} 2$ & $\mathrm{BD}^{*}(1) \mathrm{C} 28-\mathrm{C} 30$ & 18.04 \\
\hline $\mathrm{LP}(2) \mathrm{O} 3$ & BD*(1)C28-C31 & 6.81 \\
\hline $\mathrm{LP}(2) \mathrm{O} 2$ & BD*(1)O1-H44 & 2.69 \\
\hline $\mathrm{LP}(2) \mathrm{O} 2$ & BD*(1)O3-H45 & 2.70 \\
\hline
\end{tabular}




\subsubsection{Thermogravimetric Analysis (TGA)}

The TGA of the studied compound is performed over the temperature range $25-800{ }^{\circ} \mathrm{C}$ under a flowing nitrogen atmosphere and the result is shown in Figure 10. The TGA data showed that the studied compound is thermally stable up to $165^{\circ} \mathrm{C}$ then undergoes sublimation without thermal decomposition in fast step leaving almost $0 \%$ residue.

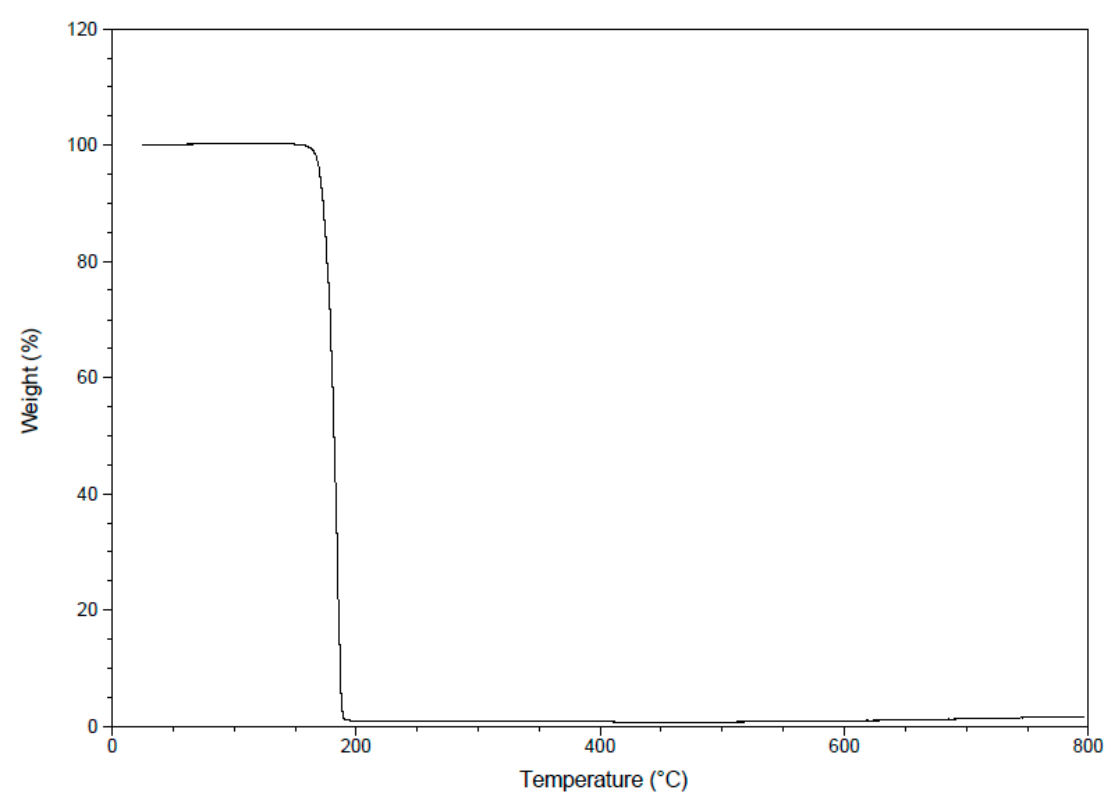

Figure 10. The TGA curve of the studied compound.

\subsection{Antimicrobial Evaluation}

In vitro antimicrobial activity of the synthesized compound was investigated against microbial activity (two Gram-positive and two Gram-negative bacteria) and against fungal activity (four fungal species). Diameter of the inhibition zone was used as a criterion for the antimicrobial activity using a well diffusion agar method [68]. The standard antimicrobial agents were used to compare the potency of the tested compound. The results are summarized in Tables 6 and 7.

Results of the in vitro antibacterial activity revealed that compound $\mathbf{1}$ shows moderate activity against all tested bacteria (Table 6). Data from the antifungal evaluation have shown that compound $\mathbf{1}$ was also potent against the four tested fungal species (Table 7). Direct graph of inhibition zone results of the synthesized compound and the references drugs is shown in Figure 11.

Table 6. Antibacterial activity of the synthesized compound $\mathbf{1}$ (Zone of inhibition; diameter in $\mathrm{mm}$ ).

\begin{tabular}{|c|c|c|c|c|}
\hline \multirow{3}{*}{ Compound } & \multicolumn{2}{|c|}{ Gram Positive Bacteria } & \multicolumn{2}{|c|}{ Gram Negative Bacteria } \\
\hline & Streptococcus pneumoniae & Bacillissubtilis & Pseudomonas aeruginosa & Escherichia coli \\
\hline & \multicolumn{2}{|l|}{ Ampicillin } & \multicolumn{2}{|c|}{ Gentamicin } \\
\hline Standard & $24 \pm 0.45$ & $32.5 \pm 0.60$ & $18.0 \pm 0.15$ & $20.0 \pm 0.21$ \\
\hline 1 & $12.5 \pm 0.31$ & $11.5 \pm 0.31$ & $10.5 \pm 0.41$ & $5.0 \pm 0.35$ \\
\hline
\end{tabular}

Data are expressed as mean $\pm \mathrm{SD}$; Standard $=25 \mu \mathrm{g} / \mathrm{mL}$. 
Table 7. Antifungal activity of the synthesized compound $\mathbf{1}$ (Zone of inhibition; diameter in $\mathrm{mm}$ ).

\begin{tabular}{ccccc}
\hline \multirow{3}{*}{ Compound } & \multicolumn{4}{c}{ Fungal Strains } \\
\cline { 2 - 5 } & Aspergillus fumigates & Syncephalastrum racemosum & Geotricum candidum & Candida albicans \\
\cline { 2 - 5 } & \multicolumn{4}{c}{ Amphotericin B } \\
\hline Standard & $24.0 \pm 0.35$ & $20.1 \pm 0.15$ & $28.5 \pm 0.45$ & $25.5 \pm 0.35$ \\
$\mathbf{1}$ & $18.0 \pm 0.15$ & $17.5 \pm 0.40$ & $23.9 \pm 0.65$ & $11.8 \pm 0.45$ \\
\hline
\end{tabular}

Data are expressed as mean $\pm \mathrm{SD}$; Standard $=25 \mu \mathrm{g} / \mathrm{mL}$.

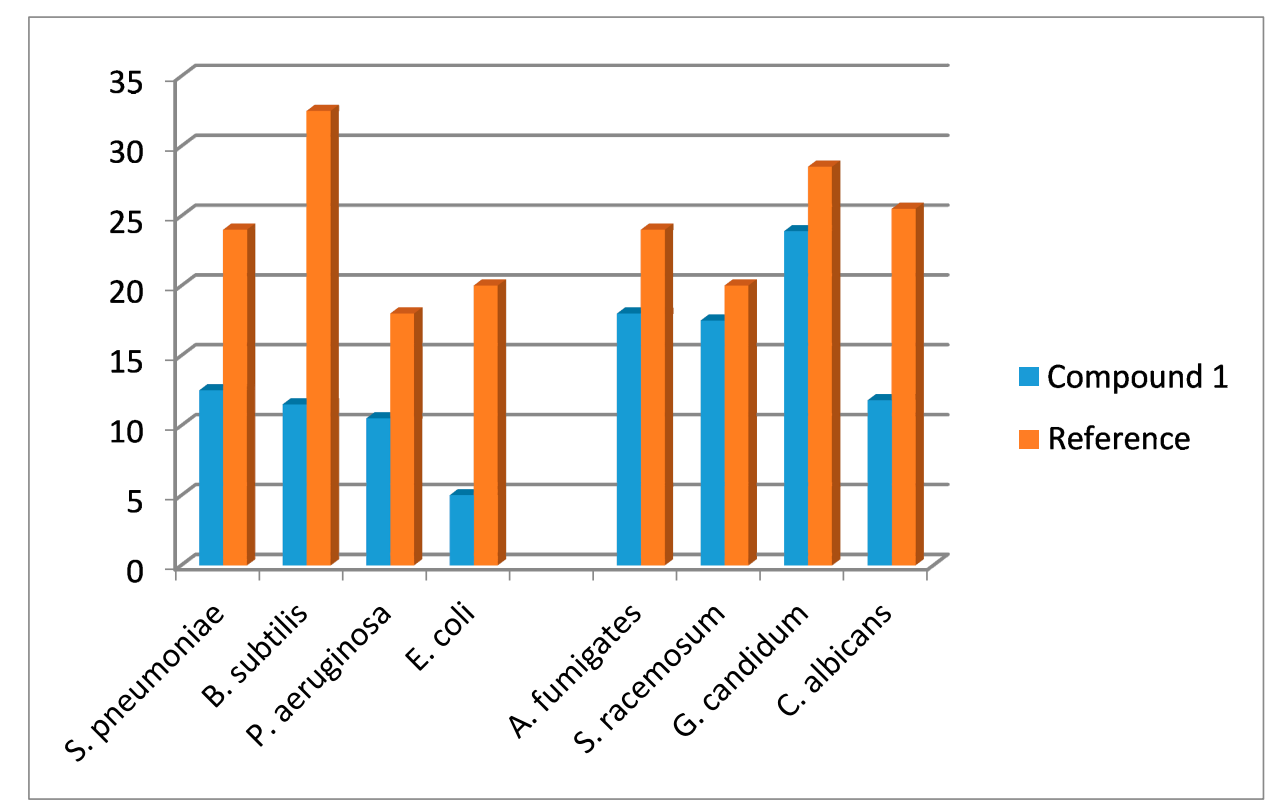

Figure 11. Inhibition zone results of the synthesized compound and the references drugs.

\subsection{Molecular Docking}

In $E$. coli, the $24 \mathrm{kda}$ domain clorobiocin (reference compound) was found to have hydrogen bonding interactions with Asp73 (1.911 $)$ ), Thr165 (2.109 $\AA), \operatorname{Asn} 46$ (2.034 $\AA)$ and Arg136 (2.071 $)$ with MolDock score -175.0 . The compound 1 revealed a MolDock score -133.5 and formed four hydrogen bonding interactions with Thr165 (2.71 $)$, Asp73 (2.56 $\AA)$, Gly77 (2.83 $)$ ) and Glu50 (3.21 $\AA$ ) (Figure 12) and this shows good interaction between the tested compound and the active site of the DNA gyrase enzyme, and also reveals a good docking result due to matching between the amino acids which interact with the tested and reference compound. Regarding the cytochrome P450 $14 \alpha$-sterol demethylase, the compound 1 revealed a MolDock score -141.2 and formed three hydrogen bonding interactions with $\operatorname{Arg} 96$ (2.96, 2.99 and $3.26 \AA$ ) (Figure 13), which supports the biological results as seen by the good antifungal activity. The compound 1 is perpendicular to the porphyrin plane heme ion with nearest distance of $2.94 \AA$. 


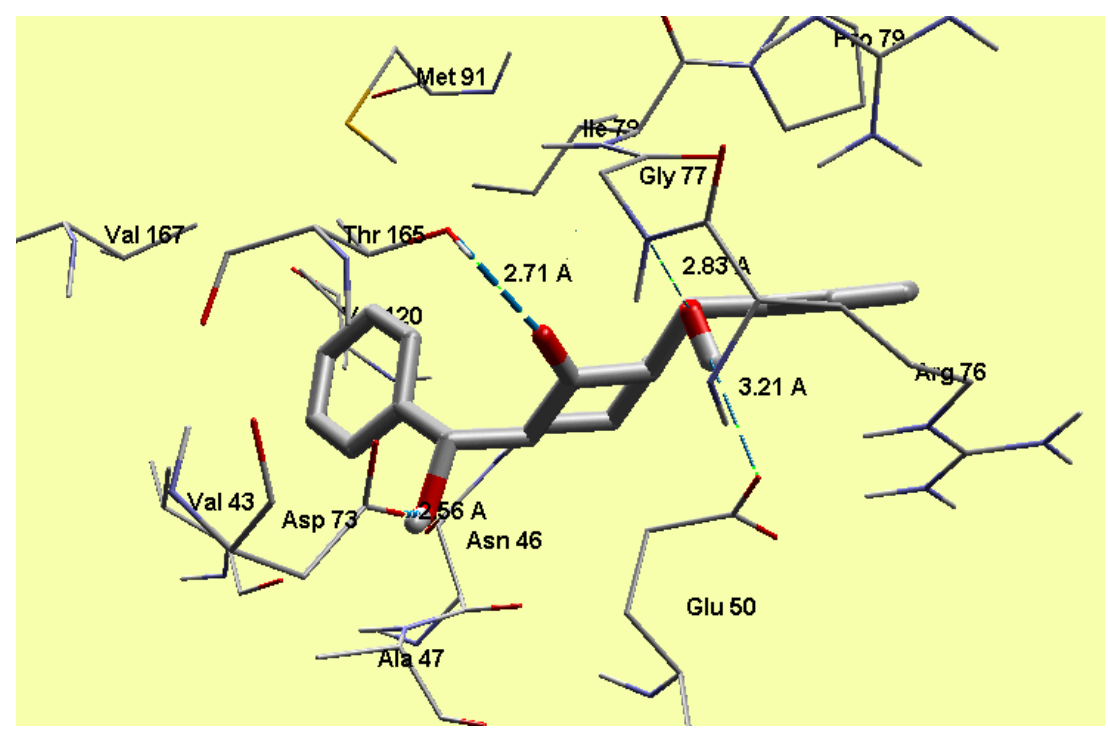

Figure 12. Interaction of compound 1 with the active site of E. coli 24 kda domain.

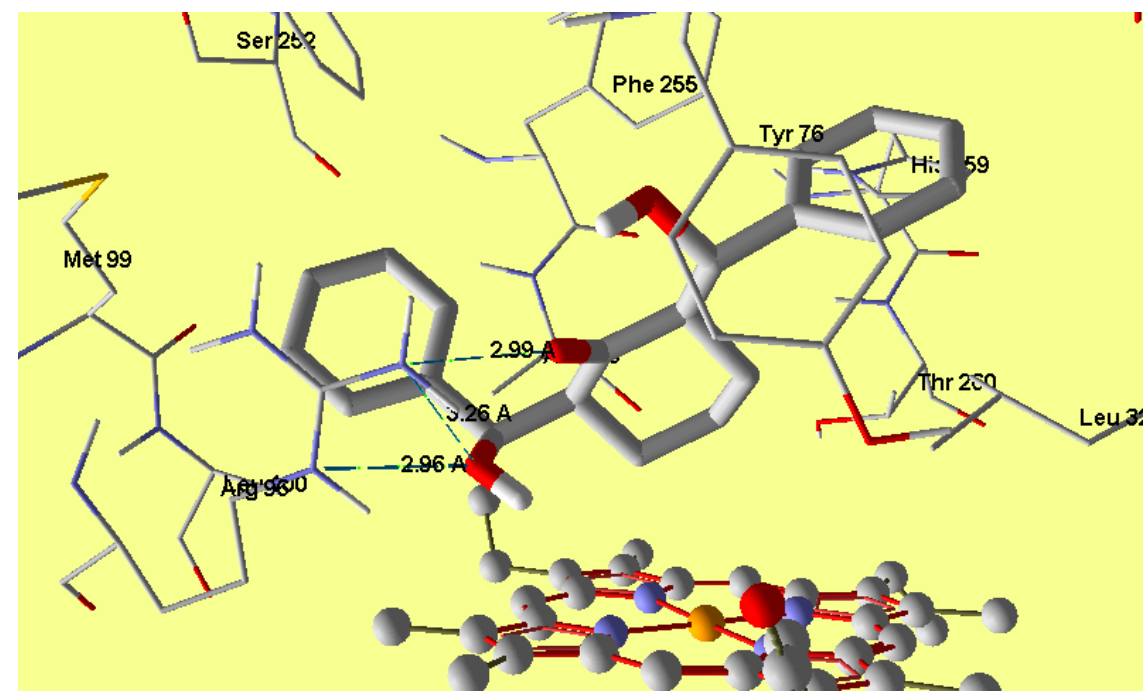

Figure 13. Interaction of compound 1 with the active site of cytochrome P450 14 $\alpha$-sterol demethylase.

\section{Experimental Section}

\subsection{General}

All the chemicals were reagent-grade, purchased from Sigma-Aldrich and Fluka, among others, and were used without further purification, unless otherwise stated. All melting points were measured on a Gallenkamp melting point apparatus in open glass capillaries and are uncorrected. IR Spectra were measured as $\mathrm{KBr}$ pellets on a Nicolet $6700 \mathrm{FT}$-IR spectrophotometer. The NMR spectra were recorded on a Jeol-400 NMR spectrometer. ${ }^{1} \mathrm{H}-\mathrm{NMR}(400 \mathrm{MHz})$, and ${ }^{13} \mathrm{C}-\mathrm{NMR}(100 \mathrm{MHz})$ were run in deuterated chloroform $\left(\mathrm{CDCl}_{3}\right)$. Chemical shifts $(\delta)$ are referred in terms of ppm and $J$-coupling constants are given in $\mathrm{Hz}$. Mass spectra were recorded on a Jeol JMS-600 H. Elemental analysis was carried out on Elmer 2400 Elemental Analyzer in CHN mode. The X-ray diffraction measurement of compound 1 was collected by using Bruker SMART APEXII D8 Venture diffractometer. The thermal analysis of the studied compound has been carried out using TGA Q500 V20.10. The wt \% loss has been 
measured from the ambient temperature up to $800{ }^{\circ} \mathrm{C}$. The electronic spectrum of the studied compound is measured using Perkin Elmer, Lambda 35, UV/Vis spectrophotometer. The experimental electronic spectra is given in Supplementary data (Figure S4).

\subsection{Preparation of 2,6-Bis(hydroxy(phenyl)methyl)cyclohexanone (1)}

A mixture of cyclohexanone $(1.5 \mathrm{mmol}, 147 \mathrm{mg})$, benzaldehyde $\left(3 \mathrm{mmol}, 320 \mathrm{mg}\right.$ ) and $\mathrm{Et}_{2} \mathrm{NH}$ ( $1.5 \mathrm{mmol}, 155.5 \mu \mathrm{L})$ in $3 \mathrm{~mL}$ of degassed $\mathrm{H}_{2} \mathrm{O}$ was stirred at room temperature for $1 \mathrm{~h}$ until TLC showed complete disappearance of the reactants. $10 \mathrm{~mL}(1 \mathrm{M} \mathrm{HCl})$ were added, extract with $\mathrm{CHCl}_{3}$, wash with brine, dried over $\mathrm{MgSO}_{4}$, evaporated and recrystallized from $\mathrm{DCM} / \mathrm{Et}_{2} \mathrm{O}$ to afford the title compound 1, as a colorless crystals $(85 \%)$, m.p. $110^{\circ} \mathrm{C}$; IR $\left(v_{\max }\right)(\mathrm{KBr}) / \mathrm{cm}^{-1} 3530,3472,3033,2911$, 2855, 1685, 1493, 1450, 1253, 1019; ${ }^{1} \mathrm{H}-\mathrm{NMR}$ (400 MHz; $\left.\mathrm{CDCl}_{3}\right)$ 7.25-7.35 (m, 10H, Ph), 4.83 (d, $2 \mathrm{H}, J=8.6 \mathrm{~Hz}, \mathrm{CHOH}), 4.01(\mathrm{brs}, 2 \mathrm{H}, \mathrm{OH}), 3.01(\mathrm{~m}, 2 \mathrm{H}, \mathrm{CH}), 1.2-1.7\left(\mathrm{~m}, 6 \mathrm{H}, \mathrm{CH}_{2}\right) ;{ }^{13} \mathrm{C}-\mathrm{NMR}$ $\left(100 \mathrm{MHz} ; \mathrm{CDCl}_{3}\right) \delta 217.06,141.01,128.26,127.81,75.06,54.51,31.36,20.75$; $\mathrm{MS} \mathrm{m} / z(\%): 310.16$ [M+ $\mathrm{M}^{+}, 98 \%$; Anal. calcd. for $\mathrm{C}_{20} \mathrm{H}_{22} \mathrm{O}_{3}$ : C, 77.39; H, 7.14; Found: C, 77.41; H, 7.15. Uv-Vis (Ethanol): 204, 231 and $328 \mathrm{~nm}$.

\subsection{Agar Diffusion Well Method to Determine the Antimicrobial Activity}

\subsubsection{Antifungal Activity of Compound 1}

Tested sample was screened in vitro for its antifungal activity against various fungi, namely, Aspergillus fumigatus (RCMB 002568), Syncephalastrumracemosum (RCMB 016001) Geotricumcandidum (RCMB 05097) and Candida albicans (RCMB 05036). The antifungal activity was performed by agar well diffusion method [68].

Fungal strains were grown in $5 \mathrm{~mL}$ Sabouraud dextrose broth (glucose/peptone; 40/10) for 3-4 days to obtain $10^{5} \mathrm{CFU} / \mathrm{mL}$ cells. The fungal culture $(0.1 \mathrm{~mL})$ was spread uniformly on the Sabouraud dextrose agar plates by sterilized triangular folded glass rod. Plates were left for 5-10 min so the culture was properly adsorbed on the surface. Then small wells $4 \mathrm{~mm} \times 2 \mathrm{~mm}$ were cut into the plates with the help of well cutter and the bottoms of the wells were sealed with $0.8 \%$ soft agar to prevent the flow of test sample at the bottom of the well. $100 \mu \mathrm{L}$ of the tested sample $(10 \mathrm{mg} / \mathrm{mL})$ was loaded into the wells of the plates. Compound 1 dissolved in DMSO, while pure DMSO was also used as control. The plates were kept for incubation at $30{ }^{\circ} \mathrm{C}$ for 3-4 days and then examined for the formation of zones of inhibition. The test was performed three times for each fungus and the average was taken. Amphotericin B was used as standard antifungal drug.

\subsubsection{Antibacterial Activity of Compound 1}

Antibacterial activities were investigated by using agar well diffusion method, against the Staphylococcus pneumonia (RCMB 010010) and Bacillus subtilis (RCMB 010067) (as Gram-positive bacteria) and Pseudomonas aeruginosa (RCMB 010043) and Escherichia coli (RCMB 0100052) (as Gram-negative bacteria). The solution of $10 \mathrm{mg} / \mathrm{mL}$ of compound in DMSO was prepared for testing against bacteria. Centrifuged pellets of bacteria from $24 \mathrm{~h}$ old culture containing approximately $10^{4}-10^{6}$ CFU (colony forming unit) per $\mathrm{mL}$ were spread on the surface of nutrient agar (type tone $1 \%$, yeast 
extract $0.5 \%, \mathrm{NaCl} 0.5 \%$, agar, and $1000 \mathrm{~mL}$ of distilled water, $\mathrm{pH} 7.0$ ) which was autoclaved under $121^{\circ} \mathrm{C}$ for at least $20 \mathrm{~min}$. Wells were created in medium with the help of sterile metallic bores and then cooled down to $45^{\circ} \mathrm{C}$. The activity was determined by measuring the diameter of the inhibition zone (in $\mathrm{mm})$. A volume of $100 \mu \mathrm{L}$ of the tested sample $(10 \mathrm{mg} / \mathrm{mL})$ was loaded into the wells of the plates. A solution of the compound was prepared in DMSO, while DMSO was also loaded as control. The plates were kept for incubation at $37{ }^{\circ} \mathrm{C}$ for $24 \mathrm{~h}$ and then the plates were examined for the formation of zones of inhibition. Each inhibition zone was measured three times by caliper to get an average value. The test was performed three times for each bacterium and the average was taken. Ampicillin and Gentamicin were used as antibacterial standard drugs [68].

\subsection{Molecular Docking}

The docking studies of ligand to proteins active sites and estimating the binding affinities of docked compound with X-ray crystal Structure of E. coli $24 \mathrm{kDa}$ Domain in complex with clorobiocin (PDB code: $1 \mathrm{KZN}$ ) and the crystal structure of cytochrome P450 14 $\alpha$-sterol demethylase (Cyp51) from Mycobacterium tuberculosis in complex with fluconazole (PDB 1EA1) were provided from Brookhaven protein data bank [69] and loaded to Molegro Virtual Docker (MVD2013.6.0.0 (win32)) program, fully functional free trial version with time limiting license [70] The non-bonded oxygen atoms of water, present in the crystal structure, was removed. MolDock score functions were used with a $0.3 \AA$ grid resolution. The binding sites were defined to any residues with $10 \AA$ distant from the cocrystallized clorobiocin and fluconazole in the complex crystal structure of the enzymes [69-72].

\section{Conclusions}

The synthesis and characterization of 2,6-bis(hydroxy(phenyl)methyl)cyclohexanone $\mathbf{1}$ is reported. The TGA analysis showed thermal stability of the studied compound up to $165{ }^{\circ} \mathrm{C}$. The molecular structure of the studied compound has been optimized using the DFT/B3LYP method and 6-311G(d,p) basis set. The calculated bond distances and bond angles showed good agreement with our reported $\mathrm{X}$-ray crystal structure. The molecular electrostatic potential picture of the studied compound has been calculated using the same level of theory. The MEP results showed that O1 and O3 are the most reactive $\mathrm{H}$-acceptor sites while the $\mathrm{H}$-atoms ( $\mathrm{H} 44$ and $\mathrm{H} 45)$ are the most reactive $\mathrm{H}$-donor sites. The $\alpha_{0}$ and HOMO-LUMO energy gap $(\Delta \mathrm{E})$ values indicated that the studied molecule is better NLO material than urea. The calculated electronic spectra using the TD-DFT method showed an intense transition band at $213.2 \mathrm{~nm}(\mathrm{f}=0.1792)$ due to $\mathrm{H} \rightarrow \mathrm{L}+1(71 \%)$ and $\mathrm{H}-4 \rightarrow \mathrm{L}+1(11 \%)$ excitations. The GIAO ${ }^{1} \mathrm{H}-$ and ${ }^{13} \mathrm{C}$-NMR chemical shift values were correlated with the experimental data. The correlation coefficients $\left(\mathrm{R}^{2}\right)$ for carbon and proton are 0.9957 and 0.9860 , respectively. The Lewis structure NBO as well as the different ICT interactions in the studied molecule have been predicted using the NBO calculations. The polarity (3.9588D) of the studied compound is due to the high percentage polarization $(81.60 \%-86.24 \%)$ at the O-atoms. The small LP(2)O2 $\rightarrow$ BD*(1)O1-H44/BD*(1)O3-H45 indicate that the $\mathrm{O} \cdots \mathrm{H}$ intramolecular $\mathrm{H}$-bonding interactions are weak. The anti-bacterial, anti-fungal and the molecular docking were investigated. Further studies of this molecule are currently under investigation in our laboratory. 


\section{Supplementary Materials}

Supplementary materials can be accessed at: http:/www.mdpi.com/1420-3049/20/07/13240/s1.

\section{Acknowledgments}

The authors would like to extend their sincere appreciation to the Deanship of Scientific Research at King Saud University for its funding this Research group NO (RG-257-1435-1436).

\section{Author Contributions}

A.B. designed the subject, prepared the manuscript; M.A. carried out the synthesis, A.M.A.-M. and Y.N.M. helped in the result and discussion section; H.A.G. and H.-K.F. carried out the X-ray analysis; H.A.G. carried out the molecular docking and S.M.S. carried out the computational studies; M.R.S. carried out the UV-Vis, IR, and TGA analyses. All authors read and approved the manuscript.

\section{Conflicts of Interest}

The authors declare no conflict of interests.

\section{References}

1. Mahrwald, R. Modern Aldol Reactions; Wiley-VCH: Weinheim, Germany, 2004; Volumes 1-2.

2. Dimmock, J.R.; Kumar, P.; Nazarali, A.J.; Motaganahalli, N.L.; Kowalchuk, T.P.; Beazely, M.A.; Quali, J.W.; Oloo, E.O.; Allen, T.M.; Szydlowski, J.; et al. Cytotoxic 2,6-bis(arylidene)cyclohexanones and related compounds. Eur. J. Med. Chem. 2000, 35, 967-977.

3. Dimmock, J.R.; Padmanilyam, M.P.; Zello, G.A.; Nienaber, K.H.; Allen, T.M.; Santos, C.L.; DeClercq, E.; Balzarini, J.; Manavathu, E.K.; Stables, J.P. Cytotoxic analogues of 2,6-bis(arylidene) cyclohexanones. Eur. J. Med. Chem. 2003, 38, 169-177.

4. Gafner, S.; Lee, S.K.; Cuendet, M.; Barthélémy, S.; Vergnes, L.; Labidalle, S.; Mehta, R.G.; Boone, C.W.; Pezzuto, J.M. Biologic evaluation of curcumin and structural derivatives in cancer chemoprevention model systems. Phytochemistry 2004, 65, 2849-2859.

5. Artico, M.; Santo, R.D.; Costi, R.; Novellino, E.; Greco, G.; Massa, S.; Tramontano, E.; Marongiu, M.E.; Montis, A.D.; Colla, P.L. Geometrically and conformationally restrained cinnamoyl compounds as inhibitors of HIV-1 integrase: Synthesis, biological evaluation, and molecular modeling. J. Med. Chem. 1998, 41, 3948-3960.

6. Costi, R.; Santo, R.D.; Artico, M.; Massa, S.; Ragno, R.; Loddo, R.; Colla, M.L.; Tramontano, E.; Colla, P.L.; Pani, A. 2,6-Bis(3,4,5-trihydroxybenzylydene) derivatives of cyclohexanone: Novel potent HIV-1 integrase inhibitors that prevent HIV-1 multiplication in cell-based assays. Bioorg. Med. Chem. 2004, 12, 199-215.

7. Piantadosi, C.; Hall, I.H.; Irvine, J.L.; Carlson, G.L. Cycloalkanones. 2. Synthesis and biological activity of $\alpha, \alpha^{\prime}$-dibenzylcycloalkanones. J. Med. Chem. 1973, 16, 770-775. 
8. Robinson, T.P.; Hubbard, R.B.; Ehlers, T.J.; Arbiser, J.L.; Goldsmith, D.J.; Bowen, J.P. Discovery and initial SAR of 2-amino-5-carboxamidothiazoles as inhibitors of the Src-family kinase p56(Lck). Bioorg. Med. Chem. 2005, 13, 4007-4010.

9. Dinkova-Kostova, A.T.; Abeygunawardana, C.; Talalay, P. Chemoprotective properties of phenylpropenoids, bis(benzylidene)cycloalkanones, and related Michael reaction acceptors: Correlation of potencies as phase 2 enzyme inducers and radical scavengers. J. Med. Chem. 1998, 41, 5287-5296.

10. Weber, W.M.; Hunsaker, L.A.; Abcouwer, S.F.; Deck, L.M.; Jagt, D.L.V. Anti-oxidant activities of curcumin and related enones. Bioorg. Med. Chem. 2005, 13, 3811-3820.

11. Raj, A.A.; Raghunathan, R.; SrideviKumari, M.R.; Raman, N. Synthesis, antimicrobial and antifungal activity of a new class of spiropyrrolidines. Bioorg. Med. Chem. 2003, 11, 407-419.

12. Rovnyak, G.; Shu, V.; Schwartz, J. Tricyclic thiazolo[3,2- $a$ ] thiapyrano[4,3- $d]$ pyrimidines and related analogs as potential anti-inflammatory agents. J. Heterocycl. Chem. 1981, 18, 327-331.

13. Deli, J.; Lorand, T.; Szabo, D.; Foldesi, A. Potentially bioactive pyrimidine derivatives. 2-Amino4-aryl-8-arylidene-3,4,5,6,7,8-hexahydroquinazoline. Pharmazie 1984, 39, 539-540.

14. Girgis, A.S.; Ibrahim, Y.A.; Mishirky, N.; Lisgarten, J.N.; Potter, B.S.; Palmer, R.A. Regioselective synthetic approaches towards 1,2,8,9-tetraazadispiro[4.1.4.3]tetradeca-2,9-dien-6-ones. Tetrahedron 2001, 57, 2015-2019.

15. Amarasekara, A.S. Nitrosation of $\beta^{\prime}$-hydroxylamino- $\alpha, \beta$-unsaturated oximes: Synthesis of 1,7-dioxa-2,6-diaza-spiro[4,4]nona-2,8-diene ring system. Tetrahedron Lett. 2005, 46, 2635-2638.

16. Hathaway, B.A. An aldol condensation experiment using a number of aldehydes and ketones. J. Chem. Educ. 1987, 64, 367-368.

17. Huitric, A.C.; Kumler, W.D. The Dipole Moments, Spectra and Structure of Some New 2-Phenyl-, 2Benzyl-, 2-(p-Halobenzylidene)- and 2,6-Bis-(p-halobenzylidene)-cyclohexanones. J. Am. Chem. Soc. 1956, 78, 614-622.

18. Adachi, I.; Yamamori, T.; Hiramatsu, Y.; Sakai, K.; Mihara, S.; Kawakami, M.; Masui, M.; Uno, O.; Ueda, M. Studies on dihydropyridines. III. Synthesis of 4,7-dihydrothieno [2,3-b]-pyridines with vasodilator and antihypertensive activities. Chem. Pharm. Bull. 1988, 36, 4389-4402.

19. Rahman, A.F.M.M.; Ali, R.; Jahng, Y.; Kadi, A.A. A Facile Solvent Free Claisen-Schmidt Reaction: Synthesis of $\alpha, \alpha^{\prime}$-bis-(substituted-benzylidene)cycloalkanones and $\alpha, \alpha^{\prime}$-bis-(substitutedalkylidene)cycloalkanones. Molecules 2012, 17, 571-583.

20. Nakano, T.; Migita, T. A convenient synthesis of $\alpha, \alpha^{\prime}$-bis(substitutedbenzylidene)cycloalkanones. Chem. Lett. 1993, 12, 2157-2158.

21. Nakano, T.; Irifune, S.J.; Umano, S.; Inada, A.; Ishii, Y.; Ogawa, M. Cross-condensation reactions of cycloalkanones with aldehydes and primary alcohols under the influence of zirconocene complexes. J. Org. Chem. 1987, 52, 2239-2244.

22. Iranpoor, N.; Kazemi, F. RuCI3 Catalyses Aldol condensations of aldehydes and ketones. Tetrahedron 1998, 54, 9475-9480.

23. Zheng, M.; Wang, L.; Shao, J.; Zhong, Q. A Facile synthesis of $\alpha, \alpha^{\prime}$-bis(substituted benzylidene) cycloalkanones catalyzed by bis( $p$-methoxyphenyl)telluroxide(bmpto) under microwave irradiation. Synth. Commun. 1997, 27, 351-354. 
24. Iranpoor, N.; Zeynizadeh, B.; Aghapour, A. Aldol Condensation of Cycloalkanones with Aromatic Aldehydes Catalysed with $\mathrm{TiCl}_{3}\left(\mathrm{SO}_{3} \mathrm{CF}_{3}\right)$. J. Chem. Res. Synop. 1999, 9, 554-555.

25. Bao, W.; Zhang, Y.; Ying, T. A Facile Route to Synthesize $\alpha, \alpha^{\prime}-b i s$ (Substituted-benzylidene) Cycloalkanones Promoted by SmI3. Synth. Commun. 1996, 26, 503-507.

26. Zheng, X.; Zhang, Y. SmI3 Catalyzed Condensation of Aliphatic Cycloketones and Aldehydes in Ionic Liquid. Synth. Commun. 2003, 33, 161-165.

27. Dewa, T.; Saiki, T.; Aoyama, Y. Enolization and Aldol Reactions of Ketone with a $\mathrm{La}^{3+}$-Immobilized Organic Solid in Water. A MicroporousEnolase Mimic. J. Am. Chem. Soc. 2001, 123, 502-503.

28. Salehi, P.; Khodaei, M.M.; Zolfigol, M.A.; Keyvan, A. Solvent-Free Crossed Aldol Condensation of Ketones with Aromatic Aldehydes Mediated by Magnesium Hydrogensulfate. Monatsh. Chem. 2002, 133, 1291-1295.

29. Yadav, J.S.; Reddy, B.V.S.; Nagaraju, A.; Sarma, J.A.R.P. Microwave assisted synthesis of $\alpha, \alpha^{\prime}$-bis(benzylidene)ketones in dry media. Synth. Commun. 2002, 32, 893-896.

30. Huang, D.F.; Wang, J.X.; Hu, Y.L. A New solvent-free synthesis of $\alpha$, $\alpha^{\prime}$-dibenzylidenecycloalkanones from acetals with cycloalkanones under microwave irradiation. Chin. Chem. Lett. 2003, 14, 333-334.

31. Zhang, X.; Fan, X.; Niu, H.; Wang, J. An ionic liquid as a recyclable medium for the green preparation of $\alpha, \alpha^{\prime}$-bis (substituted benzylidene)cycloalkanones catalyzed by $\mathrm{FeCl}_{3} \cdot 6 \mathrm{H}_{2} \mathrm{O}$. Green Chem. 2003, 5, 267-269.

32. Sabitha, G.; Reddy, G.S.K.K.; Reddy, K.B.; Yadav, J.S. Iodotrimethylsilane-mediated cross-Aldol condensation: A facile synthesis of $\alpha, \alpha^{\prime}$-bis(substituted benzylidene)cycloalkanones. Synthesis 2004, 35, 263-266.

33. Deng, G.; Ren, T. Indium Trichloride catalyzes Aldol-condensations of aldehydes and ketones. Synth. Commun. 2003, 33, 2995-3001.

34. Hu, Z.G.; Liu, J.; Zeng, P.L.; Dong, Z.B. Synthesis of $\alpha, \alpha^{\prime}$-bis(substituted benzylidene)ketones catalyzed by a $\mathrm{SOCl}_{2} / \mathrm{EtOH}$ Reagent, J. Chem. Res. Synop. 2004, 1, 55-56.

35. Zhu, Y.; Pan, Y. A new Lewis acid system Palladium/TMSCl for catalytic Aldol condensation of aldehydes with ketones. Chem. Lett. 2004, 33, 668-669.

36. Cao, Y.Q.; Zhi, D.; Zhang, R.; Chen, B.H. Aldol condensations catalyzed by PEG400 and anhydrous $\mathrm{K}_{2} \mathrm{CO}_{3}$ without solvent. Synth. Commun. 2005, 35, 1045-1049.

37. Wang, L.; Sheng, J.; Tian, H.; Han, J.; Fan, Z.; Qian, C. A convenient synthesis of $\alpha, \alpha^{\prime}$-bis(substituted benzylidene)cycloalkanones catalyzed by $\mathrm{Yb}(\mathrm{OTf})_{3}$ under solvent-free conditions. Synthesis 2004, 18, 3060-3064.

38. Li. J.; Su, W.; Li, N. Copper Triflate-catalyzed cross-Aldol condensation: A facile synthesis of $\alpha, \alpha^{\prime}$-bis(substituted benzylidene) cycloalkanones. Synth. Commun. 2005, 35, 3037-3043.

39. Das, B.; Thirupathi, P.; Mahender, I.; Reddy, K.R. Convenient and facile cross-Aldol condensation catalyzed by molecular iodine: An efficient synthesis of $\alpha, \alpha^{\prime}$-bis(substitutedbenzylidene) cycloalkanones. J. Mol. Catal. A Chem. 2006, 247, 182-185.

40. Arnold, A.; Markert, M.; Mahrwald, R. Amine-Catalyzed Aldol Condensation in the Presence of Lithium Perchlorate. Synthesis 2006, 7, 1099-1102.

41. Hazarkhani, H.; Kumar, P.; Kondiram, K.S.; ShafiGadwal, I.M. Highly selective Claisen-Schmidt condensation catalyzed by silica chloride under solvent-free reaction conditions. Synth. Commun. 2010, 40, 2887-2896. 
42. Wan, Y.; Chen, X.M.; Pang, L.L.; Ma, R.; Yue, C.-H.; Yuan, R.; Lin, W.; Yin, W.; Bo, R.C.; Wu, H. Synthesis and fluorescence properties of $\alpha, \alpha^{\prime}$-bis(substituted-benzylidene)cycloalkanones catalyzed by 1-methyl-3(2-(sulfooxy)ethyl)-1H-imidazol-3-ium chloride. Synth. Commun. 2010, 40, 2320-2328.

43. Hasaninejad, A.; Zare, A.; Balooty, L.; Mehregan, M.; Shekouhy, M. Solvent-free, Cross-Aldol condensation reaction using silica-supported, phosphorus-containing reagents leading to $\alpha, \alpha^{\prime}$-bis(arylidene)cycloalkanones. Synth. Commun. 2010, 40, 3488-3495.

44. Saito, S.S. Highly anti-Selective Catalytic Aldol reactions of amides with aldehydes. J. Am. Chem. Soc. 2006, 128, 8704-8705

45. Barakat, A.; Al-Najjar, H.J.; Al-Majid, A.M.; Soliman, S.M.; Mabkhot, Y.N.; Shaik, M.R.; Ghabbour, H.A.; Fun, H.K. Synthesis, NMR, FT-IR, X-ray structural characterization, DFT analysis and Isomerism aspects of 5-(2,6-dichlorobenzylidene)pyrimidine-2,4,6(1H,3H,5H)-trione. Spectrochim. Acta Part A 2015, 147, 107-115.

46. Barakat, A.; Al-Najjar, H.J.; Al-Majid, A.M.; Soliman, S.M.; Mabkhot, Y.N.; Ghabbour, H.A.; Fun, H.-K. Synthesis, and Molecular characterization, of 5,5'-((2,4-dichlorophenyl)methylene)bis(1,3dimethylpyrimidine 2,4,6(1H,3H,5H)-trione). J. Mol. Struct. 2015, 1084, 207-215.

47. Barakat, A.; Al-Majid, A.M.; Al-Najjar, H.J.; Soliman, S.M.; Al-Agamy, M.H.M.; Ghabbour, H.A.; Fun, H.K. Synthesis, Molecular structure investigations and antimicrobial activity of 2-thioxothiazolidin-4-one derivatives. J. Mol. Struct. 2015, 1081, 519-529.

48. Barakat, A.; Al-Najjar, H.J.; Al-Majid, A.M.; Adil, S.F.; Ali, M.; Masand, V.H.; Ghabbour, H.A.; Fun, H.K. Synthesis, X-Ray diffraction, thermogravimetric and DFT analyses of pyrimidine Derivatives. Molecules 2014, 19, 17187-17201.

49. Sheldrick, G.M. A short history of SHELX. Acta Cryst. 2008, A64, 112-122.

50. Spek. A.L. Structure validation in chemical crystallography. Acta Cryst. 2009, D65, 148-155.

51. Bruker. SMART and SAINT; Bruker AXS Inc.: Madison, WI, USA, 2001.

52. Frisch, M.J.; Trucks, G.W.; Schlegel, H.B.; Scuseria, G.E.; Robb, M.A.; Cheeseman, J.R.; Montgomery, J.A., Jr.; Vreven, T.; Kudin, K.N.; Burant, J.C.; et al. Gaussian-03, Revision C.01; Gaussian, Inc.: Wallingford, CT, USA, 2004.

53. GaussView, Version 4.1; Dennington, R., II, Keith, T., Millam, J., Eds.; Semichem Inc.: Shawnee Mission, KS, USA, 2007.

54. Zhurko, G.A.; Zhurko, D.A. Chemcraft. Lite Version Build 08. Available online: http://www. chemcraftprog.com/ (accessed on 20 July 2005).

55. Glendening, E.D.; Reed, A.E.; Carpenter, J.E.; Weinhold, F. NBO Version 3.1, CI; University of Wisconsin: Madison, WI, USA, 1998.

56. Kurt, M.; Yurdakul, S. Molecular structure and vibrational spectra of lepidine and 2-chlorolepidine by density functional theory and ab initio Hartree-Fock calculations. J. Mol. Struct. (Theochem) 2005, 730, 59-67.

57. Murray, J.S.; Sen, K. Molecular Electrostatic Potentials, Concepts and Applications; Elsevier: Amsterdam, The Netherlands, 1996.

58. Scrocco, E.; Tomasi, J. Electronic molecular structure, reactivity and intermolecular forces: An euristic interpretation by means of electrostatic molecular potentials. Adv. Quantum. Chem. 1978, $11,115-193$. 
59. Galabov, B.; Cheshmedzhieva, D.; Ilieva, S.; Hadjieva, B. Computational study of the reactivity of $\mathrm{N}$-phenylacetamides in the alkaline hydrolysis reaction. J. Phys. Chem. A 2004, 108, 11457-11462.

60. Gnanasekaran, P.; Madhavan, J. Synthesis, structural, FT-IR and non-linear optical studies of pure and Lanthanum doped L-Arginine acetate single crystals. Asian J. Chem. 2010, 22, 109-114.

61. Geskin, V.M.; Lambert, C.; Bredas, J.L. Origin of high second- and third-order nonlinear optical response in ammonio/boratodiphenylpolyene zwitterions: The remarkable role of polarized aromatic groups. J. Am. Chem. Soc. 2003, 125, 15651-15658.

62. Pu, L.S. In materials for nonlinear optics, chemical perspectives. ACS Symp. Ser. 1991, 455, 331-342.

63. Fukui, K.; Yonezawa, T.; Shingu, H.J. A molecular $\pi$ orbital theory of reactivity in aromatic hydrocarbons. J. Chem. Phys. 1952, 20, 722-725.

64. Padmaja, L.; Ravikumar, C.; Sajan, D.; Joe, I.H.; Jayakumar, V.S.; Pettit, G.R.; Neilsen, F.O. Density functional study on the structural conformations and intramolecular charge transfer from the vibrational spectra of the anticancer drug combretastatin-A2. J. Raman Spectrosc. 2009, 40, 419-428.

65. Ravikumar, C.; Joe, I.H.; Jayakumar, V.S. Charge transfer interactions and nonlinear optical properties of push-pull chromophorebenzaldehydephenylhydrazone: A vibrational approach. Chem. Phys. Lett. 2008, 460, 552-558.

66. Sebastian, S.; Sundaraganesan, N. The spectroscopic (FT-IR, FT-IR gas phase, FT-Raman and UV) and NBO analysis of 4-Hydroxypiperidine by density functional method. Spectrochim. Acta Part A 2010, 75, 941-952.

67. Hubert Joe, I.; Kostova, avikumar, R.I.C.; Amalanathan, M.; Pinzaru, S.C. Theoretical and vibrational spectral investigation of sodium salt of acenocoumarol. J. Raman Spectrosc. 2009, 40, 1033-1038.

68. Smania, E.F.A.; Monache, F.D.; Smania, A., Jr.; Yunes, R.A.; Cuneo, R.S. Triterpenes and sterols from ganodermaaustrale (Fr) Pat. (Aphyllophoromycetideae). Int. J. Med. Mushrooms. 1999, 1, 325-334.

69. PDB. A Structural View of Biology. Available online: http://www.rcsb.org/pdb (accessed on 30 March 2015).

70. Molegro Virtual Docker (MVD 2013.6.0.0). Molegro Bioinformatics Solutions, 2013, (Danish). Available online: http://www.molegro.com (accessed on 15 April 2015).

71. Lafitte. D.; Lamour, V.; Tsvetkov, P.O.; Makarov, A.A.; Klich, M.; Deprez, P.; Moras, D.; Briand, C.; Gilli, R. DNA gyrase interaction with coumarin-based inhibitors: The role of the hydroxybenzoateisopentenyl moiety and the 5'-methyl group of the noviose. Biochemistry 2002, 41, 7217-7223.

72. Banfi, E.; Scialino, G.; Zampieri, D.; Mamolo, M.G.; Vio, L.; Ferrone, M.; Fermeglia, M.; Paneni, M.S.; Pricl, S. Antifungal and antimycobacterial activity of new imidazole and triazole derivatives. A combined experimental and computational approach. J. Antimicrob. Chemother. 2006, 58, 76-84.

Sample Availability: Samples of the compound $\mathbf{1}$ are available from the authors.

(C) 2015 by the authors; licensee MDPI, Basel, Switzerland. This article is an open access article distributed under the terms and conditions of the Creative Commons Attribution license (http://creativecommons.org/licenses/by/4.0/). 